\title{
Effect of Fine Aggregate Particle Characteristics on Mechanical Properties of Fly Ash-Based Geopolymer Mortar
}

\author{
Heng $\mathrm{Li}^{1}$, Pengpeng Gao ${ }^{1}$, Fang Xu ${ }^{1, *}$, Tao Sun ${ }^{2,3, *} \mathbb{C}$, Yu Zhou ${ }^{1}$, Jing Zhu ${ }^{4}$, Chao Peng ${ }^{1}{ }^{1}$ and Juntao Lin ${ }^{1}$ \\ 1 Faculty of Engineering, China University of Geosciences, Wuhan 430074, China; li-heng@cug.edu.cn (H.L.); \\ gaopeng@cug.edu.cn (P.G.); zhouy@cnjsjk.cn (Y.Z.); pengchao@cug.edu.cn (C.P.); linjt@cug.edu.cn (J.L.) \\ 2 State Key Laboratory of Silicate Materials for Architectures, Wuhan University of Technology, \\ Wuhan 430070, China \\ 3 Wuhan University of Technology Advanced Engineering Technology Research Institute of Zhongshan City, \\ Zhongshan 528437, China \\ 4 Faculty of Road and Railway Engineering, Hubei Communications Technical College, Wuhan 430079, China; \\ xbb1220@sohu.com \\ * Correspondence: xufang@cug.edu.cn (F.X.); sunt@whut.edu.cn (T.S.)
}

\section{check for}

updates

Citation: Li, H.; Gao, P.; Xu, F.; Sun, T.; Zhou, Y.; Zhu, J.; Peng, C.; Lin, J.

Effect of Fine Aggregate Particle

Characteristics on Mechanical

Properties of Fly Ash-Based

Geopolymer Mortar. Minerals 2021, 11, 897. https://doi.org/10.3390/ $\min 11080897$

Academic Editors: Thomas

N. Kerestedjian and

Alexander Karamanov

Received: 17 July 2021

Accepted: 17 August 2021

Published: 19 August 2021

Publisher's Note: MDPI stays neutral with regard to jurisdictional claims in published maps and institutional affiliations.

Copyright: (c) 2021 by the authors. Licensee MDPI, Basel, Switzerland. This article is an open access article distributed under the terms and conditions of the Creative Commons Attribution (CC BY) license (https:// creativecommons.org/licenses/by/ $4.0 /)$.

\begin{abstract}
This research aimed to investigate the effect of fine aggregate particles on mechanical properties of fly ash-based geopolymer mortar. In this work, seven kinds of river sand particles were designed based on different fine aggregate characteristics. The fineness modulus was adopted to quantitatively describe the gradation of sands. The fluidity, compressive, flexural, and tensile strengths of geopolymer mortar with different sand gradations were analyzed by laboratory tests. Furthermore, the composition and morphology of fly ash-based geopolymer mortar was analyzed by X-ray diffraction (XRD) and scanning electron microscopy (SEM). The reasonable gradation range and filling effect of sand were obtained. The results show that fluidity and compressive and flexural strengths of geopolymer mortar both improve with the increase of the fineness modulus, while specific surface area and voidage are opposite. The tensile strength of mortar largely lies on the interface properties between the geopolymer binder and fine aggregates. When the pass rate of the key sieving size $1.18 \mathrm{~mm}$ is $75-95 \%$, the pass rate of the key sieving size $0.15 \mathrm{~mm}$ is $15-25 \%$, the fineness modulus is 2.2-2.6 and the appropriate filling coefficient of geopolymer paste is around $1.0-1.15$, the comprehensive performance of geopolymer mortar is the best. This research paper could provide a basis for the design of geopolymer mortar based on fly ash, and it is of great significance for its popularization and application.
\end{abstract}

Keywords: geopolymer mortar; fly ash; fine aggregate; gradation; fineness modulus; mechanical performance

\section{Introduction}

Cement is one of the most popular building materials in civil construction. In 2014, China's cement output reached 2.182 billion tons, accounting for $60 \%$ of the total world production [1]. Cement manufacturing releases a great amount of greenhouse gas into the environment. According to preliminary statistics, the cement industry contributes up to $5-10 \%$ by weight of the total anthropogenic emissions of carbon dioxide in the world [1-3]. As a result, the application of supplementary materials to partially displace cement and alternative cementing materials should be developed to decrease the usage of cement $[4,5]$. Geopolymer binder is one of such alternative cementing materials which are produced by mixing high alkali solutions and aluminosilicate material together [6-8]. Geopolymer has a rich source of preparation raw materials. The energy consumption and carbon emissions of geopolymer production are relatively low [9]. The $\mathrm{CO}_{2}$ emission of producing one ton of geopolymer is only about $1 / 6$ of cement production [10]. In addition, geopolymer has good mechanical properties and rapid hardening early strength 
properties, high temperature resistance, low thermal conductivity and permeability, and strong corrosion resistance [11,12]. The researchers used different raw materials to prepare the geopolymer binder. The existing research has shown that high pozzolanic activity materials, potential hydraulic materials, or aluminum silicate materials could be used as the raw materials to produce geopolymer binder [13-20]. Fly ash is one of the largest solid waste emissions from coal-fired power plants [21]. Many scholars focus on the mix design and properties studies of fly ash-based geopolymer binder [22]. Many raw materials, including zeolite or bentonite [20], palm oil fuel ash, granulated blast furnace slag [23,24], metakaolin [25-27], or flue gas desulfurization gypsum [28], were used to composite fly ash as the preparation materials of geopolymer binder. The geological polymerization is processed between these raw materials and alkaline excitation agent. Then, a range of gelation properties of inorganic polymer are formed under a certain temperature [29].

Along with cement, river sand is widely used in civil construction as a fine aggregate in mortar and concrete [30]. Sand could directly affect the main properties of geopolymer mortar. Now, many researchers have conducted a number of research works to study geopolymer mortars. Lee and Deventer [31] reported the bonding strength and the microstructure of the interface between fly ash-based geopolymers and natural siliceous aggregates. It can be seen that when the alkali-activator solution contained little or no soluble silicates, compressive strengths of geopolymer binders, mortars and concretes were obviously weaker than those activated with large dosages of soluble silicates. Temuujin [32] prepared a kind of fly ash-based geopolymer mortar with varying contents of sands and studied their mechanical and physical properties. Young's modulus and compressive strength of fly ash-based geopolymer paste were $2.27 \mathrm{GPa}$ and $60 \mathrm{MPa}$, and these values did not change obviously with the addition of up to $50 \mathrm{wt} . \%$ sands. Brough and Atkinson [33] reported that the compressive strength of geopolymer mortar prepared at room temperature can reach $40 \mathrm{MPa}$ at 7 days curing time. The mixture ratio design is GBFS: sand: excitation agent $=1: 2.33: 0.5$. The water weight accounting for the proportion of total solid quality raw materials is 0.42 . Nath [34] produced a kind of fly ash/slag geopolymer concrete with a compressive strength of $55 \mathrm{MPa}$ at room temperature. The setting time, workability and strength properties of the concrete were optimized, adopting slag content and alkali-activator content as principal variables. Lee et al. [35] studied the setting and mechanical properties of fly ash/slag geopolymer concrete and optimized slag content considering slump, setting and strength performance. Singh, B. [36] studied the influence of alkali-activator concentration on the properties of geopolymer concrete made with fly ash/slag composite mix and fluoride admixture. Yang et al. [37,38] found that fluidity of geopolymer mortar improved with the increase in the water-cement ratio and cement-sand ratio. When the sand/ratio is greater than 2.5 , the fluidity of cement mortar decreases sharply. Compared with fly ash-based geopolymer mortar, GBFS-based geopolymer mortar has a higher compressive strength and low fluidity. According to their findings, geopolymer mortar has much smaller drying shrinkage and higher brittleness than that of Portland cement mortar. In the research of Chuah, S. et al. [39], geopolymer mortars of different cation kinds, including sodium-based $(\mathrm{Na})$, potassium-based $(\mathrm{K})$, and mixed $\mathrm{Na} / \mathrm{K}$, were prepared with dune sand and river sands.

From what has been mentioned above, so far, investigations in fly ash-based geopolymer mortars mostly deal with the producing processes and effects of synthesizing parameters on mechanical and physical performance. However, in the existing literature, less research data have been available in respect to the effect of matrix internal composition structure on the mechanical performance of geopolymer mortar. In this research, a series of experiments are done to study the effect of sand content, gradation, specific surface area and voidage on mechanical properties of fly ash-based geopolymer mortar. Compressive, flexural and tensile strengths of geopolymer mortar with different sand gradations were analyzed by laboratory tests. The composition and morphology of fly ash-based geopolymer mortar was analyzed by X-ray diffraction (XRD) and scanning electron microscopy (SEM). This research can provide some reference and theory basis for the reasonable design 
of fly ash-based geopolymer mortars. It is beneficial for its application and promotion in the construction industry.

\section{Materials and Methods}

\subsection{Materials}

A type of fly ash (ASTM C618-03) [40] was used as a starting material, which was provided by Yangluo Power Plant in Wuhan, Hubei, China. Ground-granulated blastfurnace slag (GBFS) was produced by Wuhan Iron and Steel Group in Wuhan, Hubei, China. The main chemical compositions of materials measured by $\mathrm{X}$-ray fluorescence spectroscopy (XRF) were shown in Table 1.

Table 1. Chemical composition of fly ash and GBFS.

\begin{tabular}{ccc}
\hline Chemical Analysis & Fly Ash (wt.\%) & GBFS (wt.\%) \\
\hline $\mathrm{SiO}_{2}$ & 50.34 & 34.32 \\
$\mathrm{Al}_{2} \mathrm{O}_{3}$ & 35.97 & 16.06 \\
$\mathrm{Fe}_{2} \mathrm{O}_{3}$ & 3.711 & 0.334 \\
$\mathrm{MgO}$ & 0.552 & 8.6 \\
$\mathrm{CaO}$ & 4.798 & 35.04 \\
$\mathrm{Na}$ & 0.45 & 0.44 \\
$\mathrm{~K}_{2} \mathrm{O}$ & 0.812 & 0.508 \\
$\mathrm{MnO}$ & 0.053 & 0.326 \\
$\mathrm{TiO}_{2}$ & 1.361 & 0.813 \\
Loss on Ignition & 1.953 & 3.559 \\
\hline
\end{tabular}

Performance of sodium silicate was shown in Table 2. The alkali-activator used in the experiment was obtained by $\mathrm{NaOH}$-modified sodium silicate modulus to $1.2[14,41,42]$. $\mathrm{NaOH}$ used in the test is in the solid granular state. Its purity is more than $96 \%$. The water used in this research was conformed to ASTM C94 [43].

Table 2. Properties of sodium silicate.

\begin{tabular}{ccccc}
\hline Appearance & Modulus & Baume Degree (\%) & $\mathrm{Na}_{\mathbf{2}} \mathbf{O}(\%)$ & $\mathrm{SiO}_{\mathbf{2}}(\%)$ \\
\hline Colorless and transparent & 3.23 & 39.50 & 8.81 & 27.40 \\
\hline
\end{tabular}

Two kinds of sands were adopted in this research. One is standard sand, which is conformed to the ISO 679 [44] method. The other was river sands with different gradations, which were shown in Table A1 in Appendix A. Seven types of river sands $\left(K_{1}-K_{7}\right)$ were designed with a different fineness modulus. Sand gradations of river sands and standard sand $\left(K_{\mathrm{s}}\right)$ were divided into three categories according to GB/T 14684-2011 [45], which were shown in Table 3. The fineness modulus was used to characterize the fineness and coarseness of the sand. The classification of sand is used to characterize the gradation of sand. The gradation curves of river sands $\left(\mathrm{K}_{1}-\mathrm{K}_{7}\right)$ and standard sand $\left(\mathrm{K}_{\mathrm{s}}\right)$ were illustrated in Figure 1. The particle of river sands from coarse to fine are $\mathrm{K}_{1}, \mathrm{~K}_{2}, \mathrm{~K}_{3}, \mathrm{~K}_{4}, \mathrm{~K}_{5}, \mathrm{~K}_{6}$, and $\mathrm{K}_{7}$. According to GB/T 14684-2011 [45], the silt content of the river sands is below $2.0 \%$. The apparent density of river sands is between $2.65 \mathrm{~g} / \mathrm{cm}^{3}$ and $2.70 \mathrm{~g} / \mathrm{cm}^{3}$. 
Table 3. Gradation of fine aggregate.

\begin{tabular}{cccc}
\hline NO. & Fineness Modulus & Sand Type & Categories \\
\hline $\mathrm{K}_{1}$ & 3.67 & Coarse & $\mathrm{I}$ \\
$\mathrm{K}_{2}$ & 3.19 & Coarse & II \\
$\mathrm{K}_{3}$ & 2.81 & Medium & I \\
$\mathrm{K}_{4}$ & 2.39 & Medium & III \\
$\mathrm{K}_{5}$ & 2.11 & Fine & II \\
$\mathrm{K}_{6}$ & 1.61 & Fine & III \\
$\mathrm{K}_{7}$ & 1.31 & Special fine & III \\
$\mathrm{K}_{\mathrm{s}}$ & 3.0 & $/$ & $\mathrm{II}$ \\
\hline
\end{tabular}

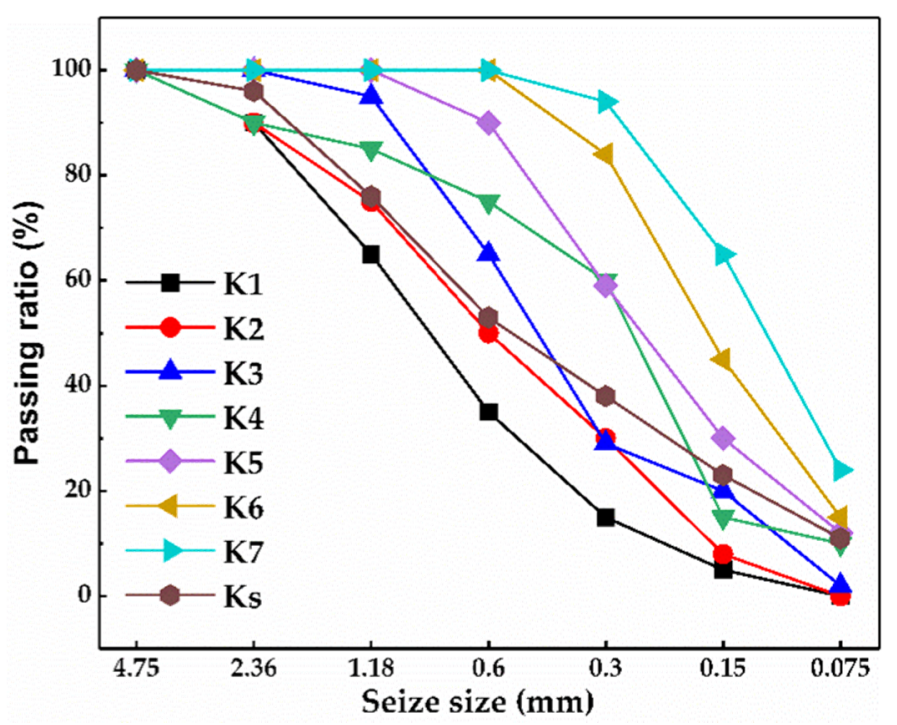

Figure 1. Gradation curve of sands.

\subsection{Methods}

2.2.1. Preparation Procedure of Fly Ash-Based Geopolymer Mortar

The preparation procedure of fly ash-based geopolymer mortar was illustrated in Figure 2. The modulus of sodium silicate can be adjusted by adding different amounts of $\mathrm{NaOH}$ reagent $[14,41,42]$. In addition, some water was evaporated due to the heat from the mixing process of the $\mathrm{NaOH}$ reagent and sodium silicate. Therefore, we used an electronic balance to weigh the mass difference of the alkali-activator before and after cooling, and extra water was added to compensate the weight loss of the water.

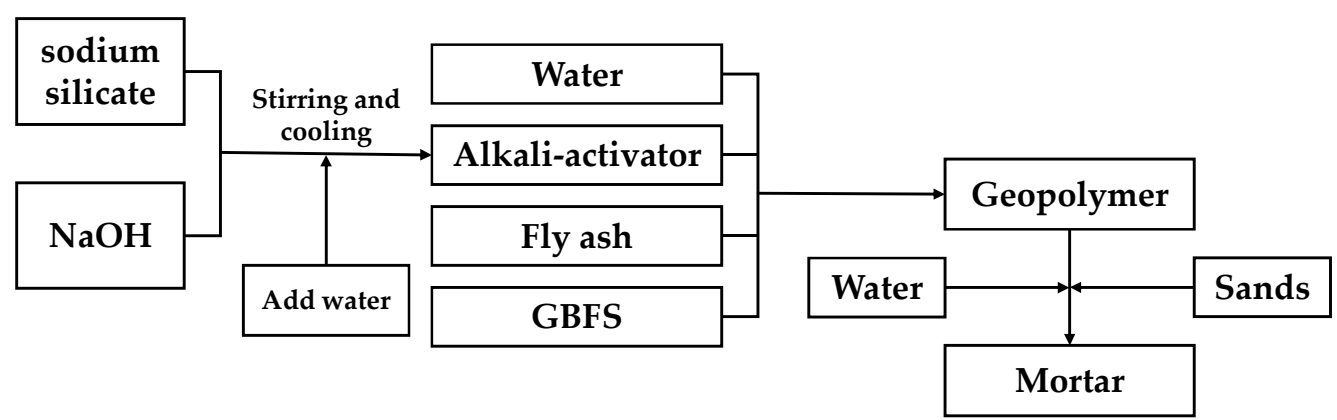

Figure 2. Preparation procedure of fly ash-based geopolymer mortar.

\subsubsection{Fluidity Property Tests}

Fluidity property tests were performed by the flow table spread (FTS) test, according to ASTM C230 [46]. The consistency of geopolymer mortar was determined by flow value. 
An average flow value of minimum and maximum diameters of FTS was measured as flow spread in $\mathrm{mm}$. The greater the flow value, the better fluidity of mortar it represents.

\subsubsection{Mechanical Performance Tests}

Compressive, flexural and tensile strength of geopolymer mortar with different sand gradations were analyzed by laboratory tests. The prism specimens were produced, adopting the mold size of $40 \mathrm{~mm} \times 40 \mathrm{~mm} \times 160 \mathrm{~mm}$ for flexural strength test and compressive strength according to ASTM C305 [47] and ASTM C348 [48] test methods. Specimens' size and test for tensile strength were illustrated in Figure 3. The tensile strength test was conducted according to ASTM C39 [49]. Three specimens were prepared for each individual mix ratio. After casting, the prism specimens were placed in their molds in a moisture room with a temperature of $23 \pm 2{ }^{\circ} \mathrm{C}$ with $98 \%$ relative humidity $(\mathrm{RH})$. After $24 \pm 2 \mathrm{~h}$, all specimens were removed from their molds, then cured in water at a temperature of $20^{\circ} \mathrm{C}$ for up to 3,7 , and 28 days.
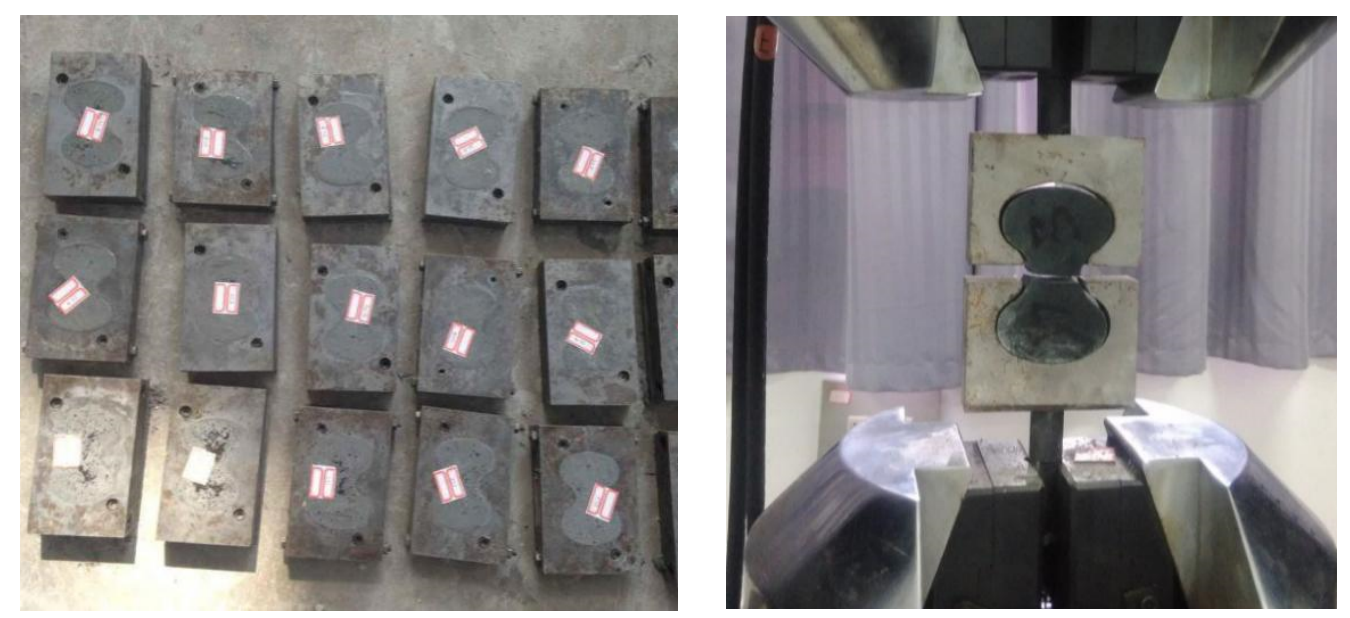

Figure 3. Sample preparation and tensile strength test.

\subsubsection{Specific Surface Area Tests}

Specific surface area models of river sand with different characteristics were established. The specific surface area of sand is used to characterize the state of sand. Assuming that the density of the same river sand is uniform, the model is a uniform sphere, and each type of river sand has seven grades. The average value of each particle size range is the diameter of particle size. The derivation formula was as follows:

$$
\begin{gathered}
N_{i}=\frac{1000 V_{i}}{\frac{4}{3} \pi R^{3}} \\
S=\sum_{i=1}^{7} 4 \pi R^{2} N_{i}
\end{gathered}
$$

where $V_{i}$ is the volume fraction of each grade in river sand; $N_{i}$ is the number of particles with grade I particle size per unit volume; $S$ is the total specific surface area of sand per unit volume, $\mathrm{m}^{2} / \mathrm{m}^{3}$.

\subsubsection{Voidage Tests}

In order to study the effect of sand particle gradation on the self-compaction of mortar, sand bulk density of the above seven different gradations was measured, and then voidage was measured. Voidage is used to characterize the filling effect of sand, which can be obtained by the following formula:

$$
\rho=1-\frac{p_{1}}{p_{2}}
$$


where $p_{1}$ is bulk density $\mathrm{kg} / \mathrm{m}^{3}$, and $p_{2}$ is apparent density $\mathrm{kg} / \mathrm{m}^{3}$.

\subsubsection{Scanning Electron Microscope Observation}

SEM analysis was carried out to get a better understanding of the microstructure of geopolymer mortar specimens. At the specified age, specimens for SEM investigations were obtained near the specimen surface. Specimens were composed of clean solid blocks, and the surface was smoothed. After sampling, specimens were immersed in alcohol to terminate hydration. Images were obtained from specimens taken from prism-size samples using a saw. Specimens were vacuum-dried overnight prior to the SEM analysis. When starting the test, specimens were coated with a thin layer of platinum before observation, and the microstructure was investigated by a SU8010 scanning electron microscope.

\subsubsection{X-ray Diffraction Tests}

At the specified age, the specimens were immersed in alcohol to terminate hydration, then specimens were firstly dried and ground into power. The testing specimens were sealed in plastic bags. The mineralogical compositions of specimens were monitored by X-ray diffraction (XRD) with a D/Max-RB diffractometer using $40 \mathrm{KV}$ and $50 \mathrm{~mA}$ current. MDI Jade (2009) software was applied to identify the crystalline phases.

\subsubsection{Mix Ratio of Fly Ash-Based Geopolymer Mortar with Standard Sands}

With respect to the mix ratio of the fly ash-based geopolymer binder, the water-binder ratio, alkali-activator dosage, GBFS/binder ratio and modulus of sodium silicate were considered as the four major mix design parameters. In this research, the water-binder ratio was adopted as $0.35,0.40$, and 0.45 , respectively. The modulus of sodium silicate was adjusted to 1.2 by $\mathrm{NaOH}[14,41,42]$. The solid mass of the alkali-activator is $14 \mathrm{wt} . \%$ to the weight of the geopolymer binder. The GBFS/binder ratio was set as $40 \%$. The geopolymer binder is the sum of fly ash, GBFS, and the solid mass of the alkali-activator. The mix ratio of geopolymer mortar samples with standard sands was shown in Table 4. The property test results of geopolymer mortar samples with standard sands were shown in Table A2 in Appendix A.

Table 4. Mix ratio of geopolymer mortar samples with standard sands.

\begin{tabular}{cccccccc}
\hline NO. & $\begin{array}{c}\text { Water-Binder } \\
\text { Ratio }\end{array}$ & $\begin{array}{c}\text { Binder-Sand } \\
\text { Ratio }\end{array}$ & Water (g) & Fly Ash (g) & GBFS (g) & $\begin{array}{c}\text { Alkali-Activator } \\
\text { (g) }\end{array}$ & $\begin{array}{c}\text { Standard } \\
\text { Sands (g) }\end{array}$ \\
\hline S1 & 0.35 & 0.3 & 67.2 & 209.0 & 139.3 & 131.2 & 1350 \\
S2 & 0.35 & 0.4 & 89.6 & 278.6 & 185.8 & 175.0 & 1350 \\
S3 & 0.35 & 0.5 & 112.0 & 348.3 & 232.2 & 218.7 & 1350 \\
S4 & 0.40 & 0.3 & 87.5 & 209.0 & 139.3 & 131.2 & 1350 \\
S5 & 0.40 & 0.4 & 116.6 & 278.6 & 185.8 & 218.7 & 1350 \\
S6 & 0.40 & 0.5 & 145.8 & 348.3 & 232.2 & 1350 \\
S7 & 0.45 & 0.3 & 107.7 & 209.0 & 139.3 & 13.2 & 1350 \\
S8 & 0.45 & 0.4 & 143.6 & 278.6 & 185.8 & 218.7 & 1350 \\
S9 & 0.45 & 0.5 & 179.5 & 348.3 & 232.2 & & 1350 \\
\hline
\end{tabular}

\subsubsection{Mix Ratio of Fly Ash-Based Geopolymer Mortar with River Sands}

The fluidity and mechanical properties tests were performed to study the influence of sand gradation on the performance of geopolymer mortar. With respect to the optimal mix ratio of the geopolymer binder in research, the water-binder ratio and binder-sand ratio were adopted as 0.35 and 0.40 , respectively. The modulus of sodium silicate was adjusted to 1.2 by $\mathrm{NaOH}[14,41,42]$. The solid mass of the alkali-activator is $14 \mathrm{wt} . \%$ to the weight of the geopolymer binder. The GBFS/binder ratio was set as $40 \%$. When the binder-sand ratio is determined, the type of sand is also one of the factors that affect the properties of the fly ash-based geopolymer mortar. The type of sand is mainly reflected by the thickness of sand, the gradation of sand, specific surface area of sand, and voidage of sand. The 
mix ratio of geopolymer mortar samples with different river sands were shown in Table 5. Property test results of geopolymer mortar samples with different grade sands were shown in Tables A3 and A4 in Appendix A.

Table 5. Mix ratio of geopolymer mortar samples with river sands.

\begin{tabular}{|c|c|c|c|c|c|c|c|c|}
\hline NO. & $\begin{array}{c}\text { Water-Binder } \\
\text { Ratio }\end{array}$ & $\begin{array}{c}\text { Binder-Sand } \\
\text { Ratio }\end{array}$ & Water (g) & Fly Ash (g) & GBFS (g) & $\begin{array}{c}\text { Alkali-Activator } \\
\text { (g) }\end{array}$ & $\begin{array}{l}\text { Sand } \\
\text { Type }\end{array}$ & $\begin{array}{c}\text { River } \\
\text { Sands (g) }\end{array}$ \\
\hline $\mathrm{K}_{1}$ & 0.35 & 0.4 & 89.6 & 278.6 & 185.8 & 175.0 & $\mathrm{~K}_{1}$ & 1350 \\
\hline $\mathrm{K}_{2}$ & 0.35 & 0.4 & 89.6 & 278.6 & 185.8 & 175.0 & $\mathrm{~K}_{2}$ & 1350 \\
\hline$K_{3}$ & 0.35 & 0.4 & 89.6 & 278.6 & 185.8 & 175.0 & $K_{3}$ & 1350 \\
\hline $\mathrm{K}_{4}$ & 0.35 & 0.4 & 89.6 & 278.6 & 185.8 & 175.0 & $\mathrm{~K}_{4}$ & 1350 \\
\hline $\mathrm{K}_{5}$ & 0.35 & 0.4 & 89.6 & 278.6 & 185.8 & 175.0 & $K_{5}$ & 1350 \\
\hline $\mathrm{K}_{6}$ & 0.35 & 0.4 & 89.6 & 278.6 & 185.8 & 175.0 & $\mathrm{~K}_{6}$ & 1350 \\
\hline $\mathrm{K}_{7}$ & 0.35 & 0.4 & 89.6 & 278.6 & 185.8 & 175.0 & $\mathrm{~K}_{7}$ & 1350 \\
\hline
\end{tabular}

\section{Results}

\subsection{Properties of Fly Ash-Based Geopolymer Mortar with Standard Sands}

\subsubsection{Flow Performance}

Figure 4 showed the influence of the water-binder ratio and binder-sand ratio on the fluidity. On one hand, when the binder-sand ratio remains unchanged, the flow value of the mortar improves along with the increase of the water-binder ratio. On the other hand, when the water-binder ratio of the mixtures were retained at the same level, the flow value increased with the increase in the binder-sand ratio. Analyzing the flow value of mortar, the flow value is less than $130 \mathrm{~mm}$ when the water-cement ratio and binder-sand ratio are both below 0.40 . The flow value of mortar decreases when more sand is added into the geopolymer paste, because the rough and angular surface area of sand traps free paste between sand particles. When the water-binder ratio is more than 0.4 and the binder-sand ratio is more than 0.45 , the flow value of geopolymer mortar is more than $210 \mathrm{~mm}$, which presents a good fluidity performance.

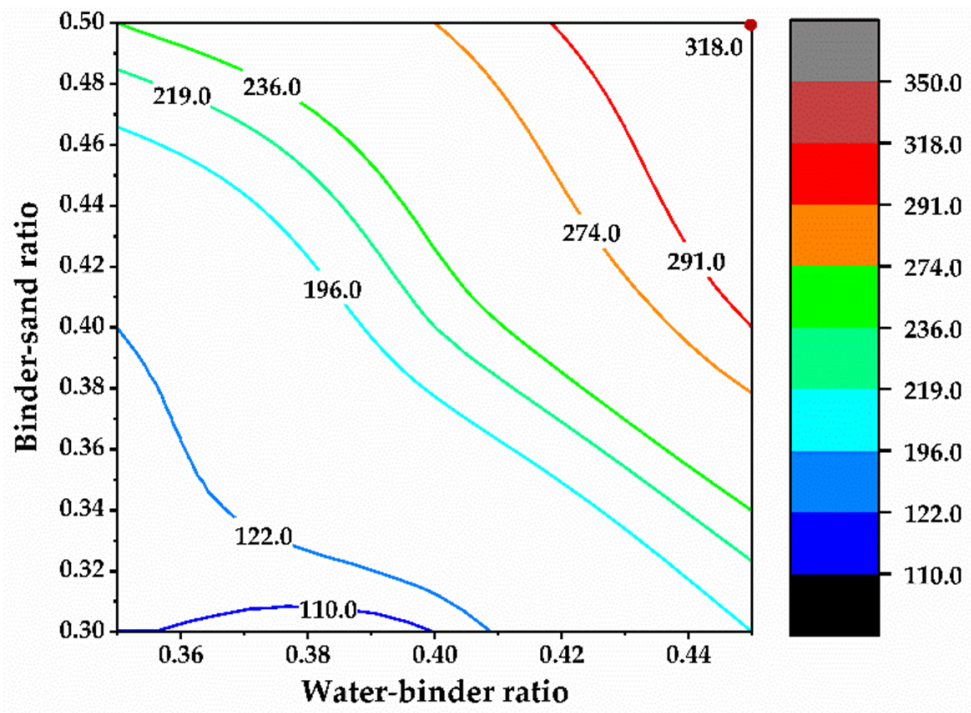

Figure 4. Influence of water-binder ratio and binder-sand ratio on the fluidity.

\subsubsection{Mechanical Performance}

The influence of the water-binder ratio and binder-sand ratio on the compressive and flexural strength of specimens cured for 28 days was shown in Figures 5 and 6 . When the water-binder ratio and binder-sand ratio are 0.35 and 0.40 , respectively, the compressive and flexural strength of mortar samples reach their peak value at $64.76 \mathrm{MPa}$ and 7.61 $\mathrm{MPa}$, 
respectively. Moreover, when binder-sand ratio is more than 0.3 , compressive and flexural strength both improve with the increase in the water-binder ratio of geopolymer mortar, and vice versa. However, when the binder-sand ratio is 0.3 , compressive and flexural strength do not have the linear relationship with the water-binder ratio. Regarding mixtures with an increasing water-binder ratio, compressive and flexural strength first improved and then decreased. It can be seen from the test results that when the optimal value range of the water-binder ratio and binder-sand ratio are $0.35-0.40$ and $0.35-0.50$, respectively, geopolymer mortar samples have good mechanical performance. The high value of compressive strength (50-70 MPa) and flexural strength (5-8 MPa) of geopolymer mortar shows great promise for constructive applications.

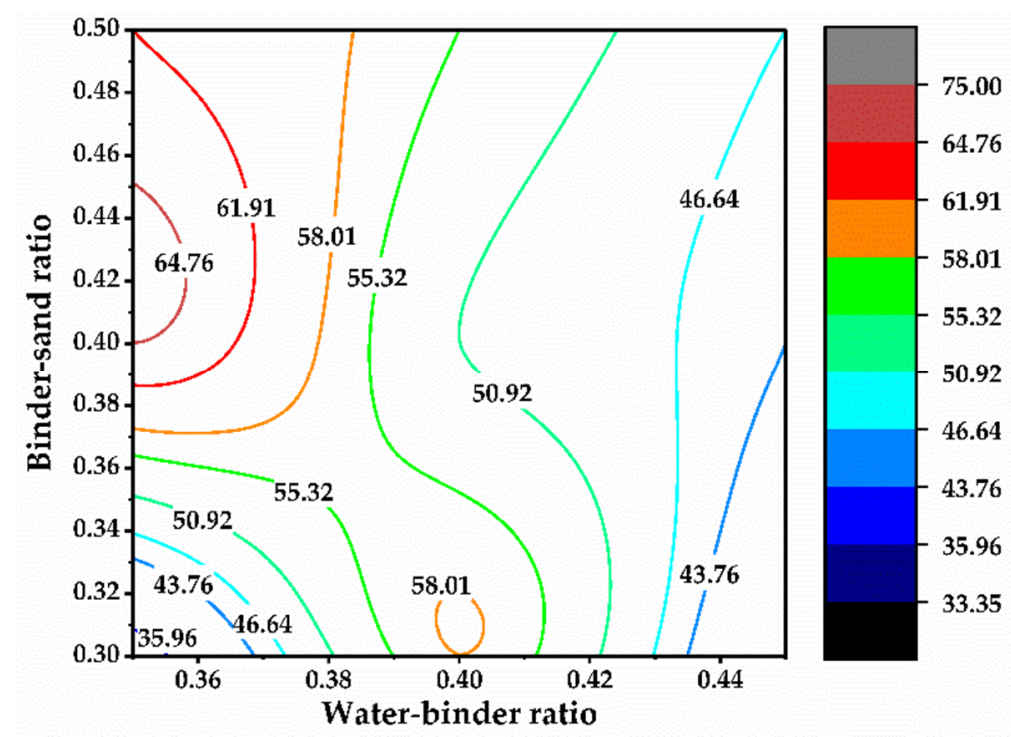

Figure 5. Influence of water-binder ratio and binder-sand ratio on $28 \mathrm{~d}$ compressive strength.

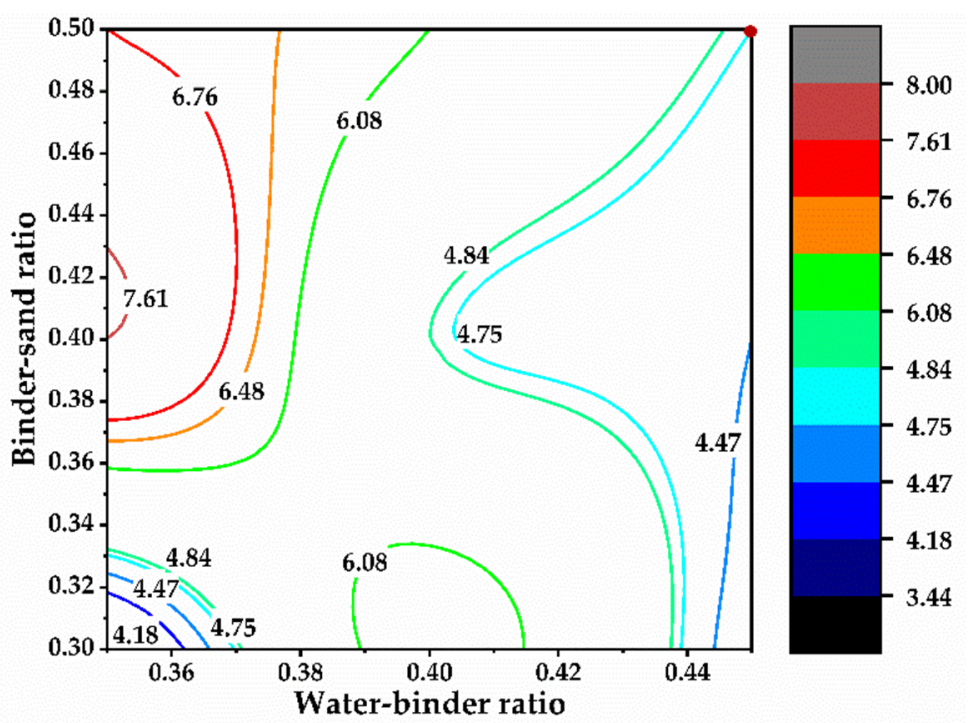

Figure 6. Influence of water-binder ratio and binder-sand ratio on $28 \mathrm{~d}$ flexural strength.

\subsection{Influence of River Sands Gradation on Performances of Mortar}

3.2.1. Specific Surface Area and Voidage of River Sands

Figure 7 shows the specific surface area and voidage of different river sands. It can be seen that as the fineness modulus increased, specific surface area and voidage showed consistency, and both gradually decreased. At the same time, when the fineness modulus 
is $3.67\left(\mathrm{~K}_{1}\right)$, the specific surface area is the smallest, and the $\mathrm{K}_{3}$ and $\mathrm{K}_{4}$ groups have the smallest voidage.

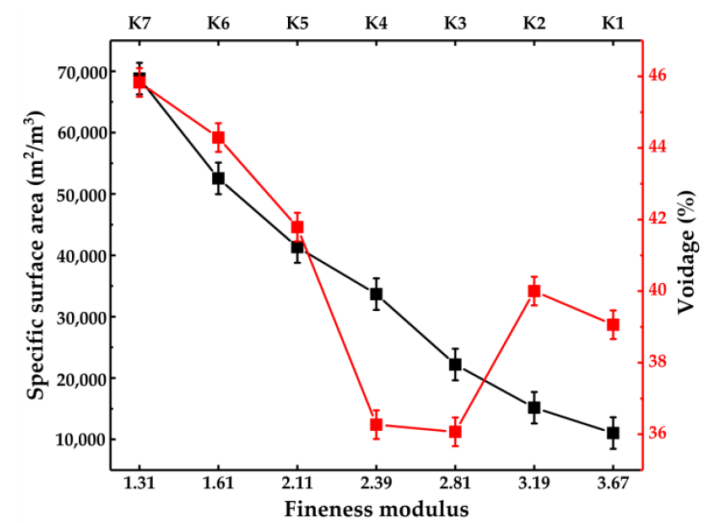

Figure 7. Relationship between the fineness modulus and specific surface area, voidage.

\subsubsection{Fluidity}

The influence of the fineness modulus on the fluidity of mortar was shown in Figure 8. The line graph observed in Figure 8 affirms the significant effect of the fineness modulus, specific surface area, and voidage on the fluidity of the geopolymer mortar. It could be seen that the flow value of mortar is approximately linearly proportional to the fineness modulus of sand. With the increase in the fineness modulus, the flow value increases gradually, while the change rule of specific surface area and voidage are completely opposite. According to the gradation curve of sand mentioned in Figure 1, it can be seen that the specimen showed better fluidity when the sand gradation belonged to I and II categories. The specific surface area is between 10,000 and $20,000 \mathrm{~mm}^{2} / \mathrm{mm}^{3}$, and voidage is about $45 \%$; the flow value of $\mathrm{K}_{2}$ sample is the best, reaching $231.30 \mathrm{~mm}$. When the gradation curve of the sand is close to the upper part of the curve map, the overall trend of fluidity is declining. This is because for samples with a low fineness modulus, there are more small particles in sands; the content of geopolymer paste is not enough to cover and bind these particles. Therefore, fluidity of the mortar decreases for the shortage of the paste. For the gradation curve near to the lower part of the curve map, the content of fine particles is less, and the content of coarse particles gradually increases. Therefore, the accumulation state of sands is obviously improved, and the fluidity of the mortar gradually increases. The change of the accumulation state results in the change of the specific surface area and voidage, which affects the fluidity of the sands. Thus, it can be seen that sand gradation, fineness modulus, specific surface area, and voidage have great influence on the fluidity of geopolymer mortar.

\subsubsection{Compressive and Flexural Strength}

The effects of fineness modulus on the compressive and flexural strength of geopolymer mortar were illustrated in Figures 9 and 10. Typically, compressive and flexural strength both improve with the increase in the fineness modulus of sands, and vice versa. Compressive strength and flexural strength of $\mathrm{K}_{1}, \mathrm{~K}_{2}, \mathrm{~K}_{3}, \mathrm{~K}_{4}$ are relatively higher, and their gradation categories are I, II, I, III, respectively. The reason is that the characteristic of geopolymer binder is one of the key factors to the mechanical strength of mortar. The sands with a smaller fineness modulus contain more fine particles, especially for those less than $0.075 \mathrm{~mm}$. This can be seen that specific surface area of sands improves with the increase in fine particles. The more specific surface area of sands is, the more the amount of geopolymer binder needs to cover and bind them. In each specimen of this experiment, the amount of geopolymer binder is constant. With respect to the sands with more fine particles, the amount of geopolymer binder is not enough to cover and binder these fine particles together, which will lead to the obvious decrease in compressive and flexural strength. The experimental data show that mechanical strength is not only related to the 
fineness modulus, but also to the technical type of sands. In general, mechanical strength of medium sand and coarse sands is higher than that of fine sands. The better the category (I, II), the higher the strength is. Compared with group $\mathrm{K}_{7}$, compressive strength and flexural strength of group $K_{1}$ increased by $19.3 \%$ and $21 \%$, respectively. Strength of geopolymer mortar is closely related to the thickness of geopolymer binder around sands. However, sand gradation has little effect on the strength of the geopolymer mortar.

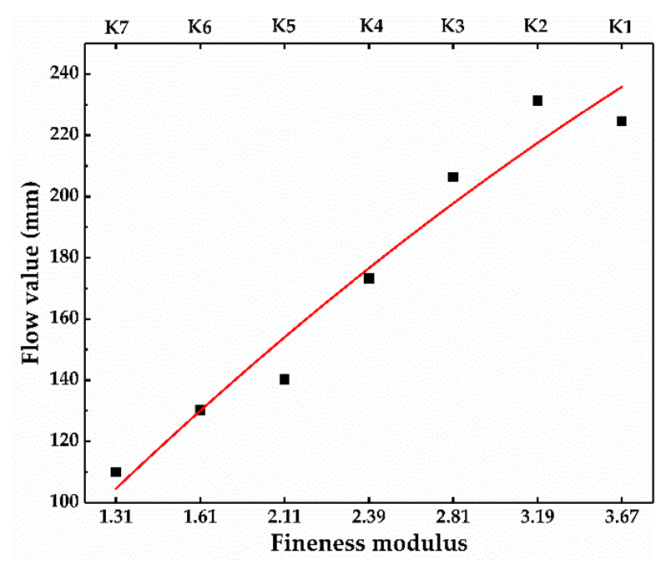

Figure 8. Influence of the fineness modulus on the fluidity of mortar.

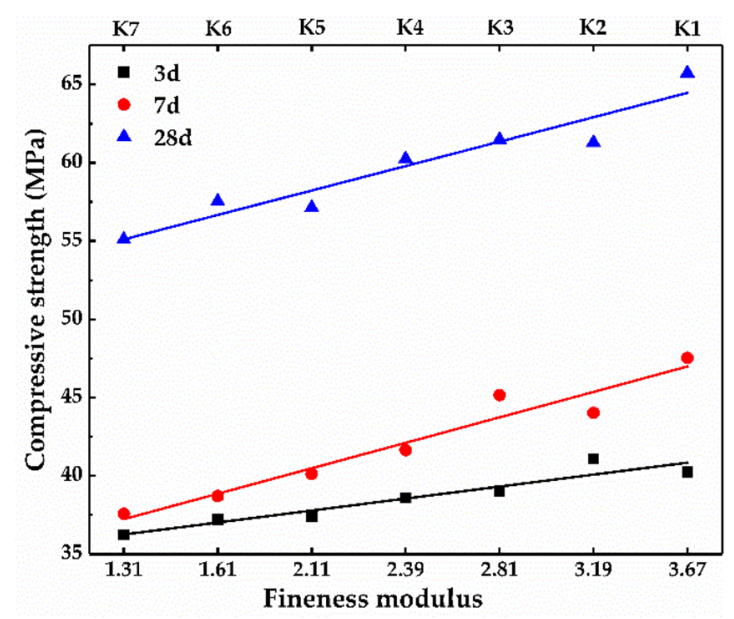

Figure 9. Influence of the fineness modulus on the compressive strength of mortar.

\subsubsection{Flexural Strength $\left(\sigma_{f}\right) /$ Compressive Strength $\left(\sigma_{c}\right)$ Ratio}

The $\sigma_{f} / \sigma_{c}$ ratio is one of the indexes used to evaluate the brittleness of cement-based materials $[50,51]$. The influence of the fineness modulus on the $\sigma_{f} / \sigma_{c}$ ratio of geopolymer mortar was illustrated in Figure 11. The $\sigma_{f} / \sigma_{c}$ ratio of geopolymer mortar does not represent the linear correlation to the fineness modulus of sands. This phenomenon is different from that of compressive and flexural strength. When the fineness modulus of sands is between 2.2 and 2.6, the specific surface area is between 35,000 and $45,000 \mathrm{~mm}^{2} / \mathrm{mm}^{3}$, and voidage is in the range of $45-47 \%$; the $\sigma_{f} / \sigma_{c}$ ratio of mortar specimens cured for 3,7 , and 28 days represents the peak value. 


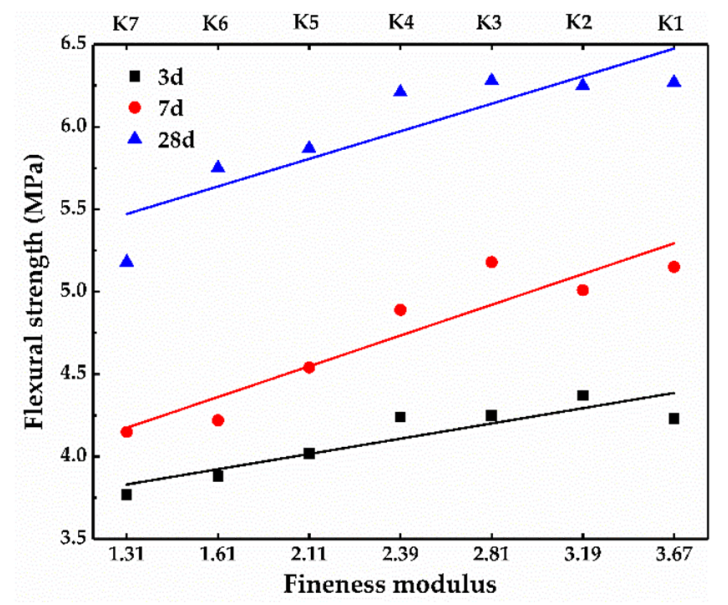

Figure 10. Influence of the fineness modulus on the flexural strength of mortar.

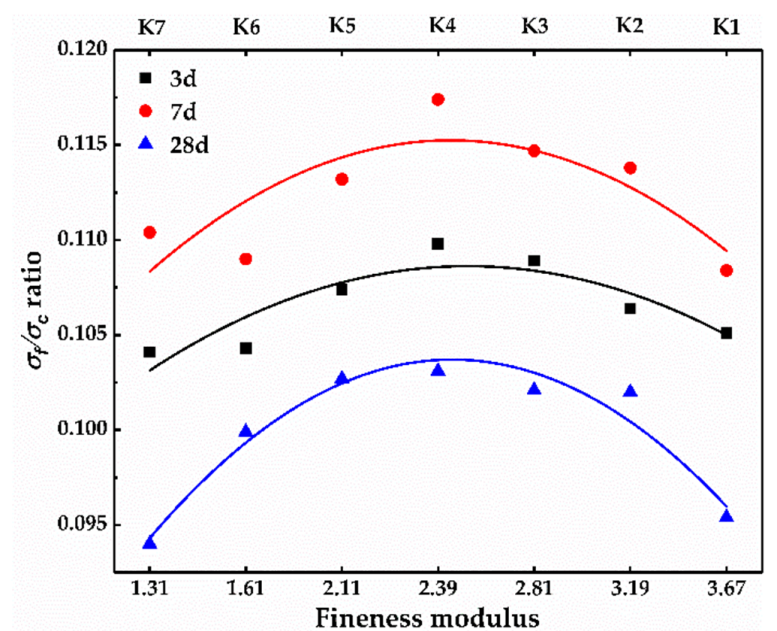

Figure 11. Influence of the fineness modulus on the $\sigma_{f} / \sigma_{\mathcal{C}}$ ratio of mortar.

\subsubsection{Tensile Strength}

Figure 12 showed the influence of the fineness modulus on the tensile strength of geopolymer mortar cured for 28 days. From test results, the tensile strength of mortar specimens first increases and then decreases as the fineness modulus increases. The specimen with a fineness modulus between 2.2 and 2.6 has the highest tensile strength, which is more than $3.9 \mathrm{MPa}$. Compared with geopolymer mortar with a fineness modulus of 3.67 , the tensile strength of mortar with a fineness modulus of 2.11 is increased by $25.6 \%$.

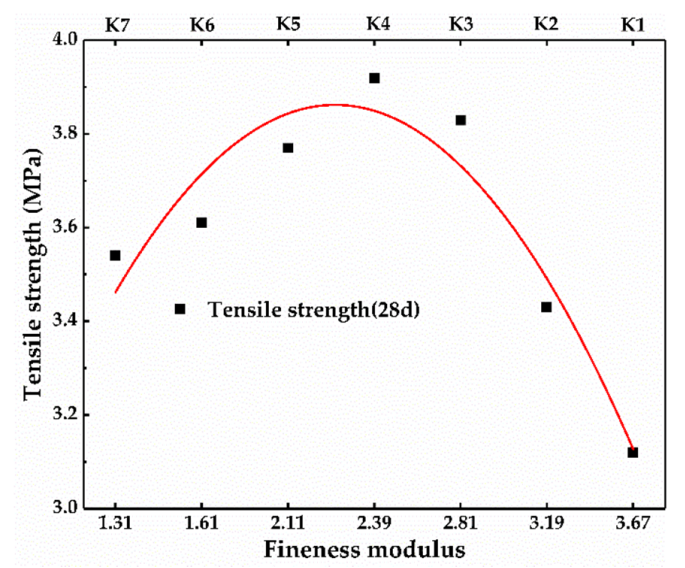

Figure 12. Influence of the fineness modulus on the tensile strength of mortar. 


\section{Discussion}

\subsection{Classification and Analysis of Packed Sands Structure in Matrix}

Particle characteristics of sand have a great effect on fluidity and mechanical properties of geopolymer mortar. Fluidity and compressive and flexural strength both improve with the increase in the fineness modulus of sand. This is because the specific surface area of sand improves with the increase in fine particles. The more fine particles in sand, the more specific the surface area of sand is. The content of geopolymer paste is not enough to cover and bond these particles. Therefore, the fluidity and compressive and flexural strength of the mortar decreases due to insufficient paste. When the fine modulus of sand is between 2.2 and 2.6, the $\sigma_{f} / \sigma_{c}$ ratio and tensile strength of the mortar are the highest. The tensile strength of mortar largely lies on the interface properties between the geopolymer binder and fine aggregates. If the fineness modulus is too small or the gradation curve far exceeds $\mathrm{K}_{4}$, the content of fine particles is more. The geopolymer binder is not enough to form a strong interface between them. Moreover, the content of large-size sand particles exists if the fineness modulus is too high, or the gradation curve is far lower than $\mathrm{K}_{3}$. The more the content of large-size sand particles, the more the defects exist in the interface. Therefore, the fineness modulus and gradation of sands have an optimal range value to ensure good tensile strength of the geopolymer mortar. The gradation and particle size distribution of sands are important characteristics in the design procedure of geopolymer mortar. Geopolymer mortar is composed of tightly packed sand particles and geopolymer paste filled in voids. As shown in Figure 13, from the perspective of internal material composition, geopolymer mortar can be divided into two parts: sand part and paste part.

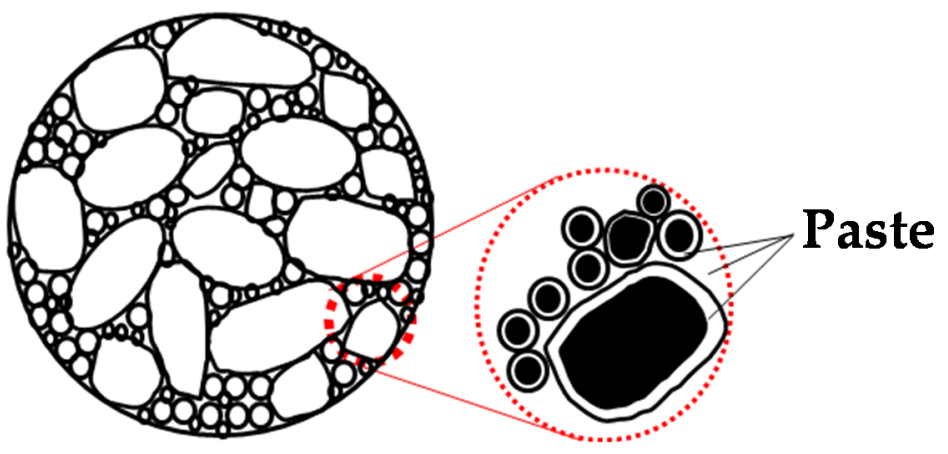

Figure 13. Schematic diagram of packed fine aggregate particles filled geopolymer paste.

The packing theory is the most commonly used method of aggregate particle gradation. It is a theory to obtain the maximum compactness through compact packing of particles. Both in terms of practicality and economy, this has great advantages. The most common such theories are the Feret packing theory, Fuller gradation curve model, and Andreasen and Andersen model. However, these three theoretical methods are more suitable for concrete with larger aggregate particles, and there are large errors for mortar with fine particles. However, the maximum compactness principle of packing theory is still applicable to mortar. In the state of maximum compactness, the mechanical properties of mortar are the best. In this paper, based on the maximum compactness principle of packing theory, referring to packing theory and according to the experimental results, the screening rate of related sieving size is proposed from the perspective of particle gradation. The voidage of sand particles can directly reflect the compactness of accumulation sand. The smaller the voidage is, the larger the bulk density of sand is. It can be seen from Figure 7 that $K_{3}$ and $K_{4}$ groups have the minimum voidage; therefore, $K_{3}$ and $K_{4}$ are the most compact and have the largest bulk density. Sand particle gradation with good continuity makes the peak values of $\sigma_{f} / \sigma_{c}$ and the tensile strength of mortar appear in $\mathrm{K}_{3}$ and $\mathrm{K}_{4}$ groups. The gradation of sand particles of better continuity can effectively reduce the void ratio between sand particles, resulting in the maximum bulk density of aggregates and reducing the amount of geopolymer paste used in the mortar matrix. Therefore, when the 
sand gradation curve is within or near the range of $K_{3}$ and $K_{4}$, the maximum compactness can be obtained. From the sand gradation curve in Figure 1, it can be seen that the Ks curve is closest to $K_{3}$ and $K_{4}$. As shown in Figure 14, the Ks curve is wrapped by $K_{3}$ and $K_{4}$ curves. Therefore, when the pass rate of the key sieving size $1.18 \mathrm{~mm}$ is $75-95 \%$, and the pass rate of the key sieving size $0.15 \mathrm{~mm}$ is $15-25 \%$, the maximum aggregate density can appear.

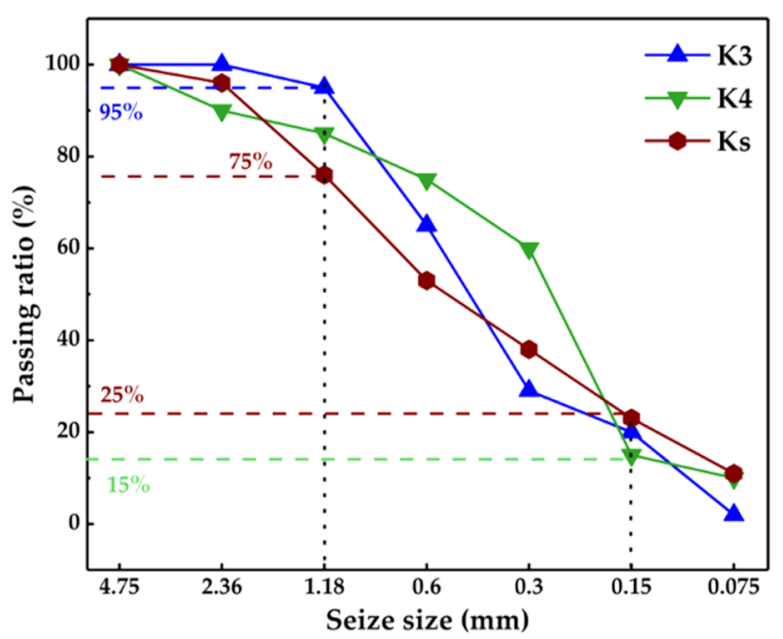

Figure 14. Gradation curve of $K_{3}, K_{4}$ and $K_{s}$.

Furthermore, the filling effect and seeding effect of fine particles in sands are two possible mechanisms on the strength development of geopolymer mortar. The fine particles in mortar could fill voids in the matrix and make it denser. The fine particles could also act as nucleation centers for the crystallization of the geopolymer matrix. The strength increases as the number of crystals increases. However, when the number of fine particles continuously improved, it was difficult to obtain a uniform matrix due to the shortage of geopolymer binder and the poor workability. The demand for geopolymer paste is determined by voids between sand particles and specific surface area of sand particles. This paper defines the paste filling coefficient as the ratio of paste volume to sand void volume, which is used to describe the balance state of sand and paste volume in geopolymer mortar. The paste volume, sand void volume, and void ratio were shown in Table A5 in Appendix A. When the filling coefficient of paste is in a certain range, fluidity and mechanical properties of geopolymer mortar are better. As shown in Figure 15, it can be seen from Figures 8-12 that when the filling coefficient of geopolymer paste is around $1.0-1.15$, the comprehensive properties of geopolymer mortar are the best.

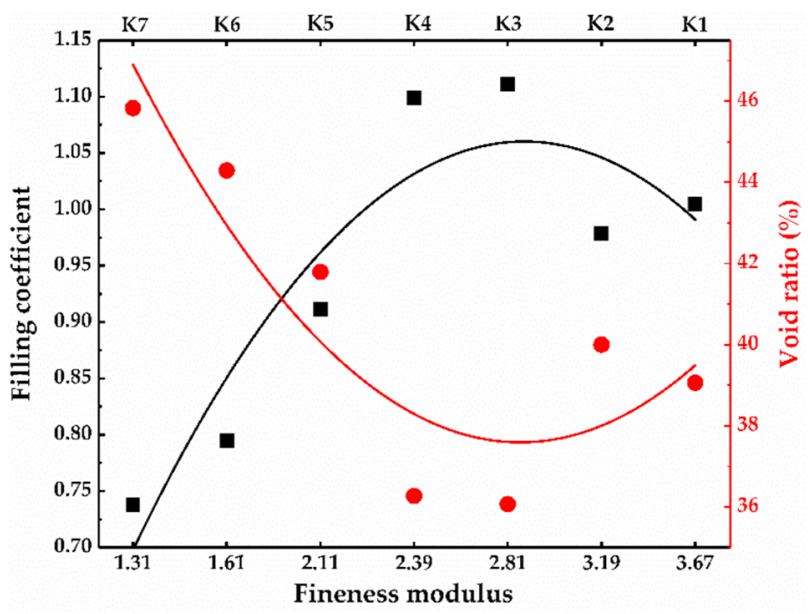

Figure 15. Filling coefficient of fly ash-based geopolymer mortar with river sands. 
Figure 16a is mainly composed of medium sand, coarser sand, and fine sand. The gradation of sand particles is a continuous gradation. After adding fine aggregate, the voidage of sand particles is the smallest, and the content of geopolymer paste can fill these voids sufficiently to bond sand particles tightly, and the geopolymer paste fill coefficient is the largest. Therefore, no large pores are found in the mortar structure. According to the maximum compactness principle of packing theory, this mortar structure is the most compact. It has compressive and tensile properties. According to the experimental results, the $\sigma_{f} / \sigma_{c}$ ratio of $\mathrm{K}_{3}$ and $\mathrm{K}_{4}$ is the largest and the fluidity can reach more than $200 \mathrm{~mm}$. The tensile, compressive, and flexural strengths are above $3.8 \mathrm{MPa}, 60 \mathrm{MPa}$, and $6.0 \mathrm{Mpa}$, respectively.

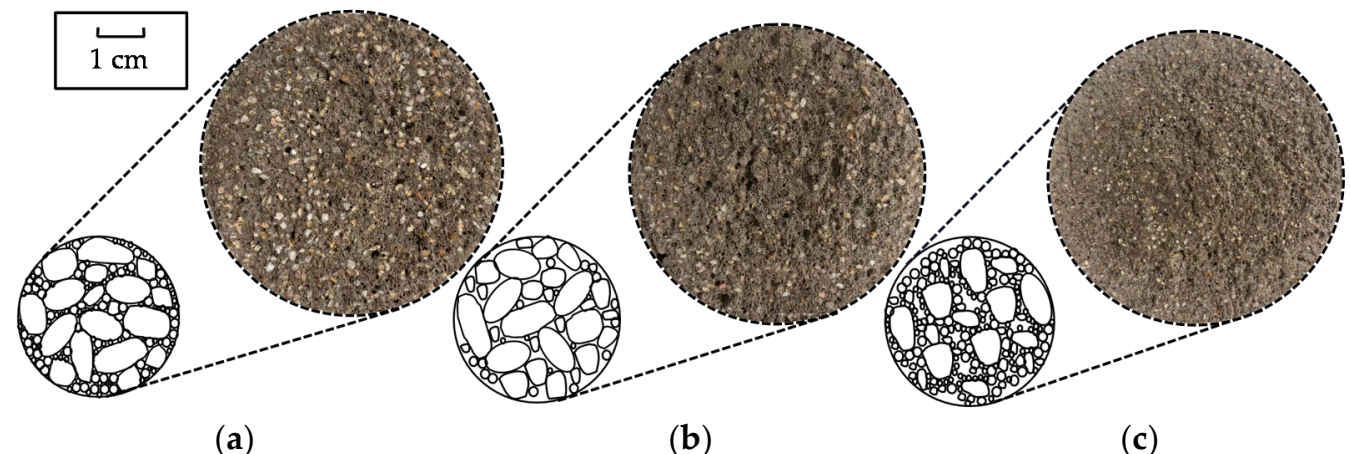

(a)

(b)

(c)

Figure 16. Geopolymer mortar structure with different fine aggregates gradation. (a) Geopolymer mortar structure with continuous gradation; (b) Geopolymer mortar structure composed of with medium sand and coarser sand; (c) Geopolymer mortar structure with discontinuous intermittent gradation.

Figure $16 \mathrm{~b}$ is mainly composed of medium sand and coarser sand. Although particle gradation is continuous, it lacks fine sand filling. It can be seen from Figure 7 that $\mathrm{K}_{1}$ and $\mathrm{K}_{2}$ groups are mainly composed of coarse sand particles with relatively large voids. The content of geopolymer paste is not enough to fill these voids. The fill coefficient is also lower, as shown in Figure 15; therefore sand particles cannot be tightly bonded together, resulting in the structure of this kind of geopolymer mortar having compressive characteristics but not tensile characteristics. Therefore, the tensile strength of $K_{1}$ and $K_{2}$ is the lowest, but the aggregate mainly composed of coarse sand particles has a better framework support effect. Therefore, the compressive and flexural strength of $K_{1}$ and $K_{2}$ show good performance. However, according to packing theory, this type is not the most compact state.

Figure 16c is mainly composed of finer sands. The fine sands surround a small number of coarser sands. The lack of medium sand and coarser sand filling is a discontinuous intermittent gradation; the experimental groups are specifically represented by the $\mathrm{K}_{6}$ and $K_{7}$ groups. Due to the presence of a large number of fine particles, the content of geopolymer paste is not enough to cover and bond these particles. Therefore, the fluidity is the lowest. In addition, the "squeezing effect" of finer sands on coarser sands is obvious. The intermittent distribution of sands lacks necessary framework support, and sand particle structure presents a suspended state. Therefore, it can neither resist pressure nor resist pull. The physical and mechanical properties of geopolymer mortar are affected to a certain extent. Therefore, the mechanical properties of $\mathrm{K}_{6}$ and $\mathrm{K}_{7}$ geopolymer mortar are poor.

\subsection{XRD Analysis}

Some literature studies use FTIR and XRD to analyze microstructure of geopolymer to support XRD analysis results [52,53]. In future work, we will also use more methods to conduct more microscopic studies on geopolymer. In this paper, XRD is used to analyze the phase of GBFS, fly ash, and geopolymer paste, and results are shown in Figure 17. Fly ash sample contains a small amount of mullite and quartz [52,53], mainly for its 
amorphous state. There is no obvious crystal phase in the XRD pattern of GBFS. The main mineral composition of GBFS slag is also the amorphous glassy state, which is the same as that of fly ash. With respect to the geopolymer paste sample, the main mineral components are quartz and mullite, which are mainly from fly ash. In geopolymer paste, GBFS and fly ash themselves contain a large amount of amorphous glassy state materials, as well as amorphous glassy state materials generated by geopolymerization and hydration in geopolymer paste; these amorphous glassy state materials are wrapped in quartz and mullite crystal, therefore the diffraction peaks of quartz and mullite in geopolymer paste are significantly lower than that in fly ash. The crystalline structure of hydrated calcium silicate is found in the geopolymer paste sample. This is mainly due to the slag containing large amounts of $\mathrm{CaO}$ and $\mathrm{SiO}_{2} . \mathrm{SiO}_{2}$ generates sodium silicate in the process of hydration. $\mathrm{Ca}^{2+}$ reacts with sodium silicate $\mathrm{SiO}_{4}{ }^{4-}$ in the process of hydration to generate the hydrated calcium silicate. In 2 Theta between $15-40^{\circ}$, the XRD of fly ash shows a broad hump, and the broad hump is not changed in the geopolymer paste; this is consistent with the findings of most scholars [54-57]. Liew et al. [58] believe that the broad hump corresponds to the amorphous aluminosilicate. Figure 17 XRD analysis results show that the broad hump is sillimanite and quartz. The main chemical components of sillimanite, quartz, and aluminosilicate are $\mathrm{Al}_{2} \mathrm{O}_{3}$ and $\mathrm{SiO}_{2}$. Sillimanite is composed of double-stranded aluminosilicate; therefore, the broad hump is characteristic of the aluminosilicate diffraction peak, which is consistent with research results of Liew et al. [58]. It shows that broad hump is formed by geopolymerization.

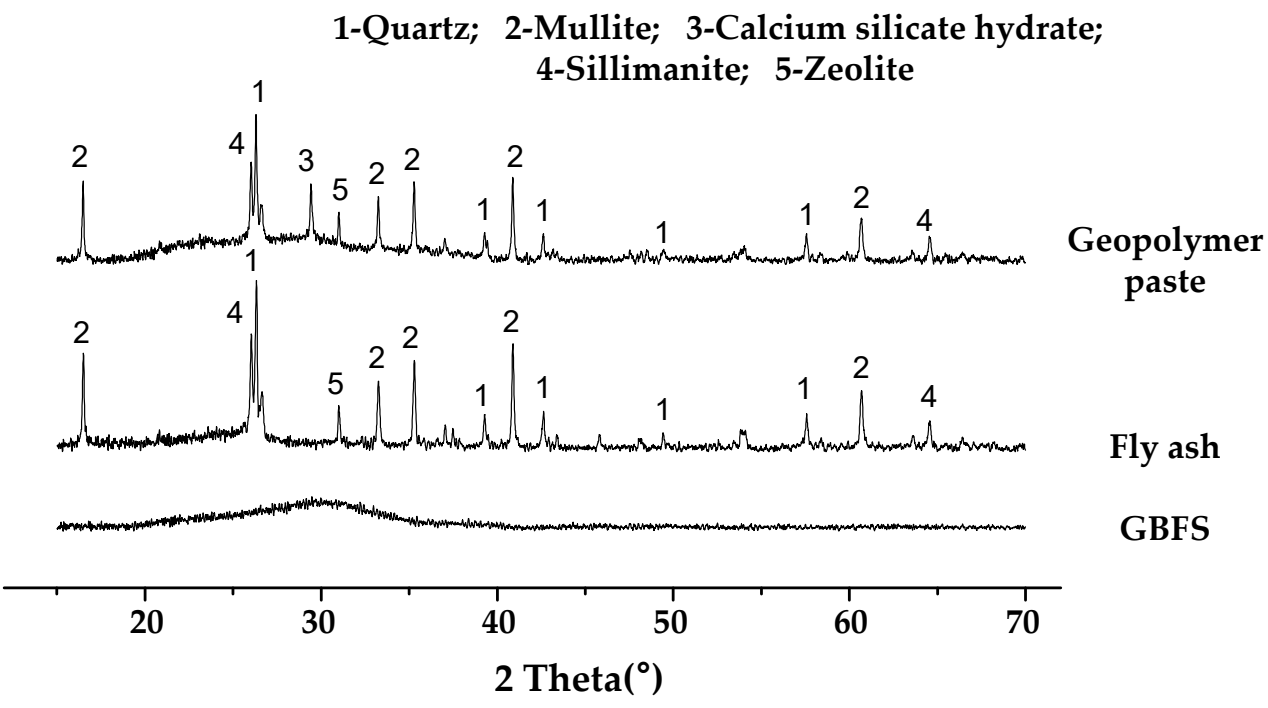

Figure 17. XRD patterns of GBFS, fly ash and geopolymer paste.

In the hydration process of geopolymer paste, with the structure decomposition of fly ash and GBFS particles, the geological polymerization reaction is processed between active silica and active alumina. At the same time, C-S-H gel is generated by $\mathrm{Ca}^{2+}$ in the paste. In this way, the geopolymer network structure is formed in the matrix. Therefore, the content of hydration products directly affects the geopolymer network structure.

\subsection{SEM Analysis}

The microstructure of the geopolymer paste sample cured for 28 days was shown in Figure 18. Under SEM at micro level, geopolymer matrix does not exhibit any noticeable cracks on the surface of the specimen. A large number of network structures of gel are observed in the micrograph of geopolymer paste sample. Gel network structures are porous and rough. It can be observed that some undissolved fly ash glass microspheres are packed by the gel. Figure 19 shows the hydration products completely filled gel pores and fully reacted fly ash particles. As the hydration process intensified, gel crystallized 
into a large number of white crystals. Combined with XRD analysis, it can be seen that a large number of white crystals are calcium silicate hydrate [59]. In addition, there are a few small white crystals. According to the results of scanning electron spectroscopy, XRD, and Liew et al. [58], it can be judged that the main component of these small white crystals is aluminosilicate [21,59], and they are wrapped by hydration products and a large number of amorphous glassy state materials. This is also consistent with FTIR analysis results [53].

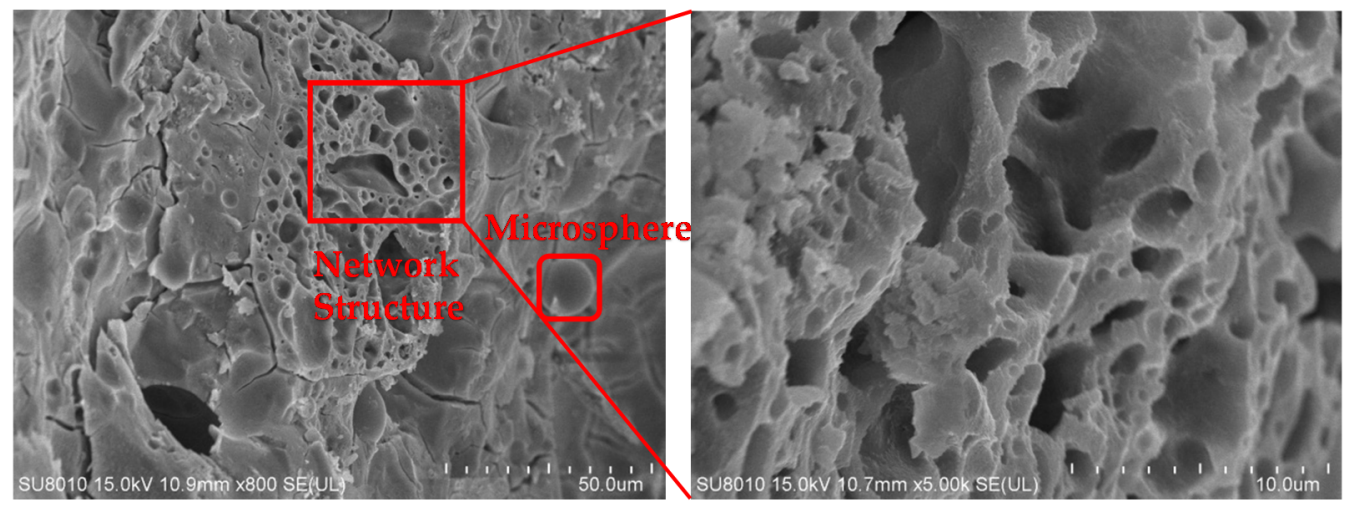

Figure 18. Micrographs (SEM) of geopolymer paste.

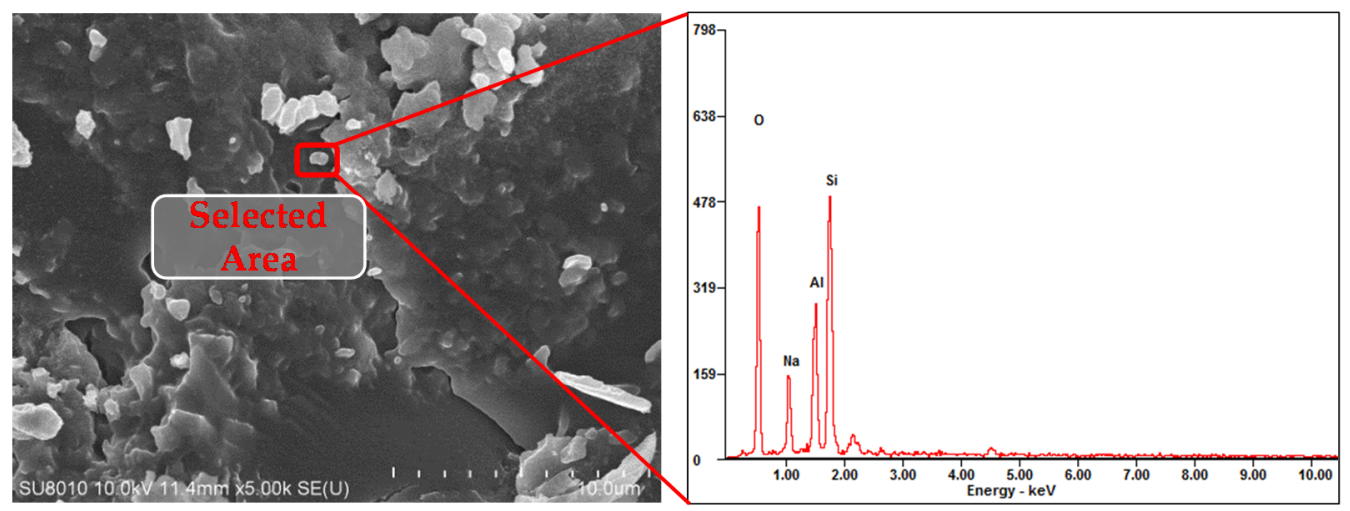

Figure 19. Scanning electron spectroscopy of geopolymer paste.

Figure 20 showed the micrographs of fly ash and GBFS in geopolymer samples. It can be seen that there are glass microspheres of fly ash particles inside the mortar matrix. Microspheres have a smooth shell and fly ash particles have a porous interior [60]. The surfaces of GBFS micro particles are relatively rough, and large amount of amorphous glassy state materials exist. This is also proven by XRD analysis of GBFS. As the hydration process intensified, fly ash and GBFS micro particles could not be observed by SEM, which indicates that fly ash and GBFS micro particles have completely reacted to form a geopolymer matrix. The geopolymer matrix gradually contacted with sand and formed an obvious interfacial transition zone (ITZ), as shown in Figure 21. In this experiment, the amount of geopolymer binder is constant. If the content of fine aggregate is more, the content of geopolymer paste is not enough to cover and bind these particles. Therefore, the fluidity and compressive and flexural strength of $\mathrm{K}_{5}, \mathrm{~K}_{6}$ and $\mathrm{K}_{7}$ are poor. However, if the fineness modulus is too high, there is a content of large-size sand particles. The more the content of large-size sand particles, the more the defects that exist in the interface. As shown in Figure 21a, ITZ is long, and has long and wide gaps. Therefore, mechanical properties of $\mathrm{K}_{1}$ and $\mathrm{K}_{2}$ are also poor. When the fineness modulus of sands is between 2.2 and 2.6, it is clear that there is an intimate bonding between the geopolymer matrix and sands. As shown in Figure 21b, sand is gradually wrapped by hydration products, forming a dense structure. Therefore, $K_{3}$ and $K_{4}$ have the best tensile strength. A close observation 
of the interfacial region uncovered that the bonding property of geopolymer matrix is good enough to produce an intimate interface. In this way, the quantity of aluminosilicate and the interface between sand particles and gel in the geopolymer matrix has significant bearing on the overall development mechanical strength of the material.
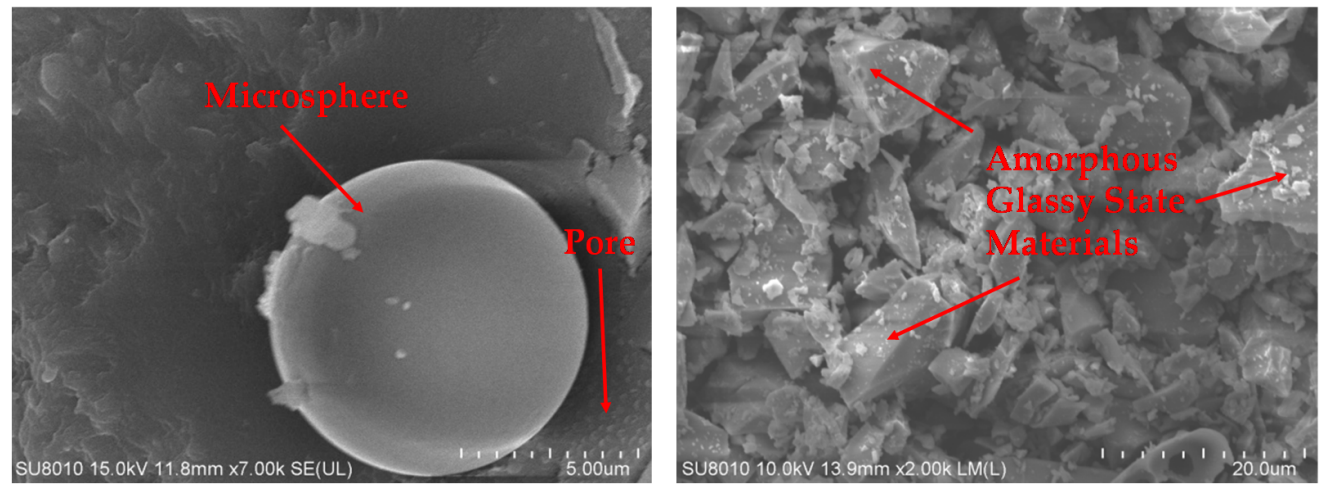

Figure 20. Micrographs (SEM) of fly ash and GBFS in geopolymer mortar.
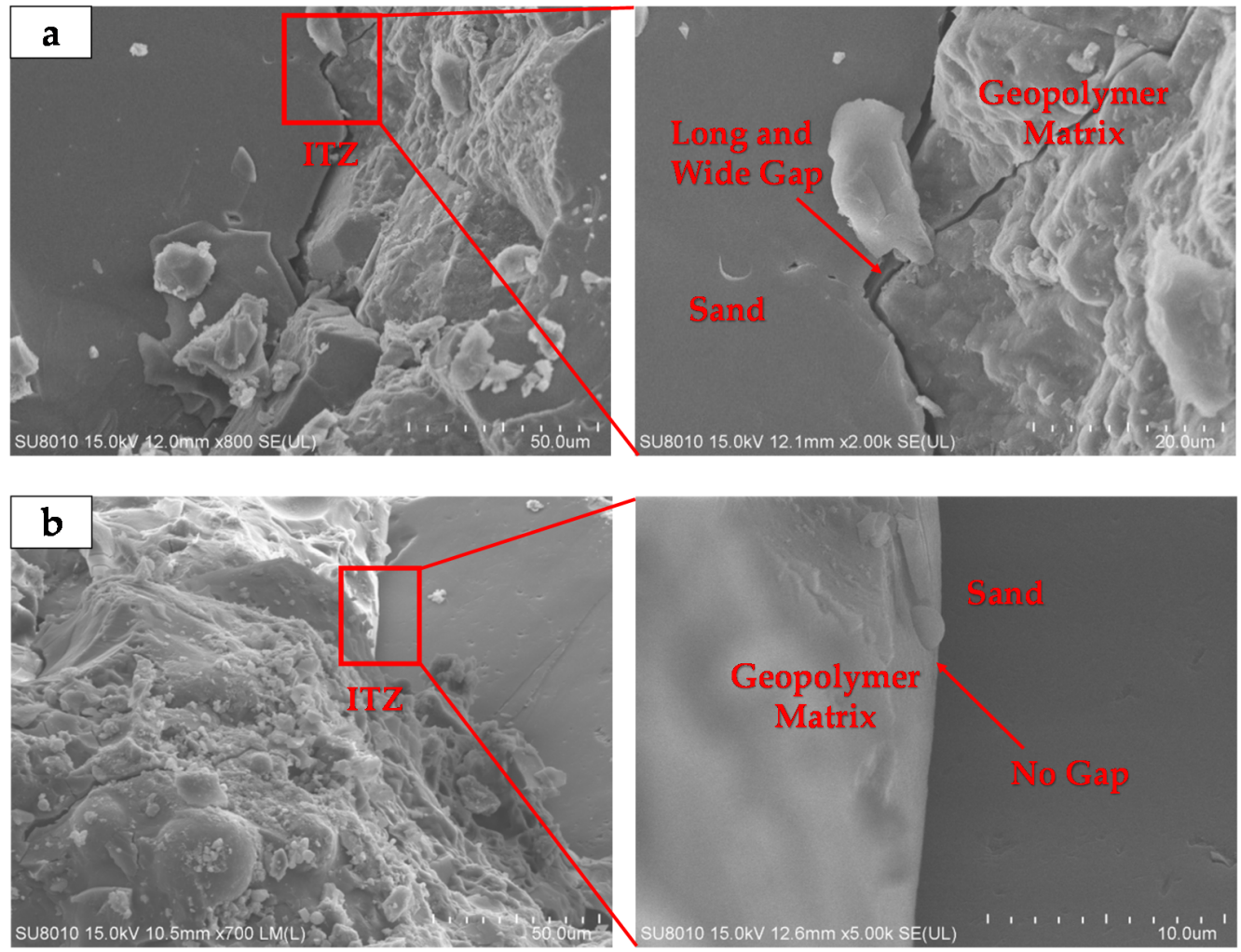

Figure 21. Micrographs (SEM) of ITZ between geopolymer matrix and sand. (a) ITZ with defects; (b) ITZ with intimate bonding.

\section{Conclusions}

Based on the results obtained in this research, the following conclusions could be drawn:

(1) When the water-cement ratio is more than 0.4 and the binder-sand ratio is more than 0.45 , the fluidity of the geopolymer mortar with standard sand presents a good fluidity property. When the water-binder ratio and binder-sand ratio are in range of $0.35-0.40$ and $0.35-0.50$, respectively, geopolymer mortar samples with standard sand have good mechanical performance. The high value of compressive strength (50-70 MPa) and flexural strength (5-8 MPa) shows great promise for construction applications. 
(2) For the fluidity of the geopolymer mortar, the gradation and fineness modulus of river sands both have great influence on it. The flow value of the mortar is approximately linearly proportional to the fineness modulus of sands. Geopolymer mortar has better fluidity when the sand gradation belongs to I and II categories.

(3) The compressive and flexural strength of geopolymer mortar both improve with the increase of the fineness modulus of sands, while specific surface area and voidage are opposite. Tensile strength first increases and then decreases as the fineness modulus increases; this is contrary to the law of specific surface area and voidage. Moreover, if sand gradation belongs to I and II categories, specimens of geopolymer mortar will show relatively higher strength.

(4) When the pass rate of the key sieving size $1.18 \mathrm{~mm}$ is $75-95 \%$, the pass rate of the key sieving size $0.15 \mathrm{~mm}$ is $15-25 \%$, fineness modulus is $2.2-2.6$, and the appropriate filling coefficient of geopolymer paste is around 1.0-1.15, the maximum density of packed sands could appear. The $\sigma_{f} / \sigma_{c}$ ratio of geopolymer mortar is the largest; the fluidity can reach more than $200 \mathrm{~mm}$. The tensile, compressive, and flexural strengths are above 3.8 $\mathrm{MPa}, 60 \mathrm{MPa}$, and $6.0 \mathrm{Mpa}$, respectively. At this time, the comprehensive performance of geopolymer mortar is the best. Therefore, geopolymer mortar should be prepared with medium sand with good gradation.

(5) The geopolymer composites have crystal diffraction peak forms of quartz, mullite, hydrated calcium silicate, sillimanite, and zeolite in their crystalline phases. The results of microscopic tests indicate that a large number of network structures of gel are observed in the micrograph of geopolymer paste samples. Whether the interfacial transition zone (ITZ) between the geopolymer matrix and sand particles is dense determines the tensile strength performance of geopolymer mortar.

Author Contributions: Data curation, H.L. and P.G.; writing—original draft preparation, H.L.; writing - review and editing, H.L.; methodology, F.X., T.S., C.P. and J.L.; formal analysis, Y.Z.; investigation, P.G. and Y.Z.; resources, F.X., T.S., C.P. and J.L.; validation, J.Z. All authors have read and agreed to the published version of the manuscript.

Funding: This research was funded by The Third Batch of Special Fund for Science and Technology Development of Zhongshan City in 2020 (2020-18), Research Project of Wuhan University of Technology Advanced Engineering Technology Research Institute of Zhongshan City (WUT202011),Science and Technology Project of Hubei Transportation Department (2020-2-1-10).

Institutional Review Board Statement: Not applicable.

Informed Consent Statement: Not applicable.

Data Availability Statement: Not applicable.

Acknowledgments: The authors would like to acknowledge the financial support from The Third Batch of Special Fund for Science and Technology Development of Zhongshan City in 2020 (2020-18), Research Project of Wuhan University of Technology Advanced Engineering Technology Research Institute of Zhongshan City (WUT202011), Science and Technology Project of Hubei Transportation Department (2020-2-1-10).

Conflicts of Interest: The authors declare no conflict of interest. 


\section{Appendix A}

Table A1. The gradation of fine aggregate.

\begin{tabular}{ccccccccccc}
\hline $\begin{array}{c}\text { Seize } \\
\text { Size (mm) }\end{array}$ & $\mathbf{4 . 7 5}$ & $\mathbf{2 . 3 6}$ & $\mathbf{1 . 1 8}$ & $\mathbf{0 . 6}$ & $\mathbf{0 . 3}$ & $\mathbf{0 . 1 5}$ & $\mathbf{0 . 0 7 5}$ & $\begin{array}{c}\text { Fineness } \\
\text { Modulus }\end{array}$ & Categories \\
\hline & $\mathrm{K}_{1}$ & 100 & 90 & 65 & 35 & 15 & 5 & 0 & 3.67 & $\mathrm{I}$ \\
& $\mathrm{K}_{2}$ & 100 & 90 & 75 & 50 & 30 & 8 & 0 & 3.19 & $\mathrm{II}$ \\
Passing & $\mathrm{K}_{3}$ & 100 & 100 & 95 & 65 & 29 & 20 & 2 & 2.81 & $\mathrm{I}$ \\
ratio $(\%)$ & $\mathrm{K}_{4}$ & 100 & 90 & 85 & 75 & 60 & 15 & 10 & 2.39 & III \\
& $\mathrm{K}_{5}$ & 100 & 100 & 100 & 90 & 59 & 30 & 12 & 2.11 & II \\
& $\mathrm{K}_{6}$ & 100 & 100 & 100 & 100 & 84 & 45 & 15 & 1.61 & III \\
& $\mathrm{K}_{7}$ & 100 & 100 & 100 & 100 & 94 & 65 & 24 & 1.31 & III \\
& $\mathrm{Ks}$ & 100 & 96 & 76 & 53 & 38 & 23 & 11 & 3.0 & II \\
\hline
\end{tabular}

Table A2. The test results of geopolymer mortar with standard sands.

\begin{tabular}{ccccc}
\hline NO. & $\begin{array}{c}\text { Fluidity } \\
\mathbf{( m m )}\end{array}$ & $\begin{array}{c}\text { 28d Compressive } \\
\text { Strength/ } \sigma_{\boldsymbol{c}} \mathbf{( M P a )}\end{array}$ & $\begin{array}{c}\text { 28d Flexural } \\
\left.\text { Strength/ } \sigma_{f} \mathbf{( M P a}\right)\end{array}$ & The $\sigma_{f} / \sigma_{\boldsymbol{c}}$ Ratio \\
\hline S1 & 110 & 33.35 & 3.44 & 0.1031 \\
S2 & 122 & 64.76 & 7.61 & 0.1175 \\
S3 & 236 & 61.91 & 6.76 & 0.1092 \\
S4 & 110 & 58.01 & 6.48 & 0.1117 \\
S5 & 219 & 50.92 & 4.84 & 0.0951 \\
S6 & 274 & 55.32 & 6.08 & 0.1099 \\
S7 & 196 & 35.96 & 4.18 & 0.1162 \\
S8 & 291 & 43.76 & 4.47 & 0.1021 \\
S9 & 318 & 46.64 & 4.75 & 0.1018 \\
\hline
\end{tabular}

Table A3. The flow value and tensile strength of mortar with different fineness modulus.

\begin{tabular}{|c|c|c|c|c|c|c|c|}
\hline NO. & $\begin{array}{l}\text { Fineness } \\
\text { Modulus }\end{array}$ & Sand Type & Category & $\begin{array}{c}\text { Specific } \\
\text { Surface Area } \\
\left(\mathrm{m}^{2} / \mathrm{m}^{3}\right)\end{array}$ & $\begin{array}{c}\text { Voidage } \\
(\%)\end{array}$ & $\begin{array}{l}\text { Flow Value } \\
\quad(\mathrm{mm})\end{array}$ & $\begin{array}{l}\text { 28d Tensile } \\
\text { Strength } \\
\text { (MPa) }\end{array}$ \\
\hline $\mathrm{K}_{1}$ & 3.67 & Coarse & $\mathrm{I}$ & $11,039.06$ & $39.06 \%$ & 224.67 & 3.12 \\
\hline $\mathrm{K}_{2}$ & 3.19 & Coarse & II & $15,163.13$ & $40.00 \%$ & 231.30 & 3.43 \\
\hline $\mathrm{K}_{3}$ & 2.81 & Medium & I & $22,192.67$ & $36.07 \%$ & 206.43 & 3.83 \\
\hline $\mathrm{K}_{4}$ & 2.39 & Medium & III & $33,680.16$ & $36.27 \%$ & 173.27 & 3.92 \\
\hline $\mathrm{K}_{5}$ & 2.11 & Fine & II & $41,342.14$ & $41.79 \%$ & 140.28 & 3.77 \\
\hline $\mathrm{K}_{6}$ & 1.61 & Fine & III & $52,535.01$ & $44.29 \%$ & 130.22 & 3.61 \\
\hline $\mathrm{K}_{7}$ & 1.31 & Special fine & III & $68,802.19$ & $45.83 \%$ & 110.00 & 3.54 \\
\hline
\end{tabular}

Table A4. The compressive, flexural strength of mortar with different fineness modulus.

\begin{tabular}{cccccccccc}
\hline \multirow{2}{*}{ NO. } & \multicolumn{3}{c}{ Compressive Strength $\left(\sigma_{c}\right)$} & \multicolumn{3}{c}{ Flexural Strength $\left(\sigma_{f}\right)$} & \multicolumn{3}{c}{ The $\sigma_{f} / \sigma_{\boldsymbol{c}}$ Ratio } \\
\cline { 2 - 10 } & $\mathbf{3 d}$ & $\mathbf{7 d}$ & $\mathbf{2 8 d}$ & $\mathbf{3 d}$ & $\mathbf{7 d}$ & $\mathbf{2 8 d}$ & 3d & 7d & 28d \\
\hline $\mathrm{K}_{1}$ & 40.25 & 47.53 & 65.72 & 4.23 & 5.15 & 6.27 & 0.1051 & 0.1084 & 0.0954 \\
$\mathrm{~K}_{2}$ & 41.08 & 44.02 & 61.29 & 4.37 & 5.01 & 6.25 & 0.1064 & 0.1138 & 0.1020 \\
$\mathrm{~K}_{3}$ & 39.04 & 45.16 & 61.48 & 4.25 & 5.18 & 6.28 & 0.1089 & 0.1147 & 0.1021 \\
$\mathrm{~K}_{4}$ & 38.6 & 41.64 & 60.24 & 4.24 & 4.89 & 6.21 & 0.1098 & 0.1174 & 0.1031 \\
$\mathrm{~K}_{5}$ & 37.43 & 40.12 & 57.13 & 4.02 & 4.54 & 5.87 & 0.1074 & 0.1132 & 0.1027 \\
$\mathrm{~K}_{6}$ & 37.21 & 38.71 & 57.54 & 3.88 & 4.22 & 5.75 & 0.1043 & 0.1090 & 0.0999 \\
$\mathrm{~K}_{7}$ & 36.23 & 37.58 & 55.11 & 3.77 & 4.15 & 5.18 & 0.1041 & 0.1104 & 0.0940 \\
\hline
\end{tabular}


Table A5. The filling coefficient of geopolymer paste in the mortar matrix.

\begin{tabular}{ccccc}
\hline NO. & $\begin{array}{c}\text { Relative Paste } \\
\text { Volume }(\mathbf{m L})\end{array}$ & Void Ratio (\%) & $\begin{array}{c}\text { Relative Void } \\
\text { Volume (mL) }\end{array}$ & $\begin{array}{c}\text { Filling } \\
\text { Coefficient }\end{array}$ \\
\hline $\mathrm{K}_{1}$ & 380.1 & $39.06 \%$ & 378.35 & 1.005 \\
$\mathrm{~K}_{2}$ & 380.1 & $40.00 \%$ & 388.43 & 0.979 \\
$\mathrm{~K}_{3}$ & 380.1 & $36.07 \%$ & 342.21 & 1.111 \\
$\mathrm{~K}_{4}$ & 380.1 & $36.27 \%$ & 345.94 & 1.099 \\
$\mathrm{~K}_{5}$ & 380.1 & $41.79 \%$ & 417.13 & 0.911 \\
$\mathrm{~K}_{6}$ & 380.1 & $44.29 \%$ & 478.21 & 0.795 \\
$\mathrm{~K}_{7}$ & 380.1 & $45.83 \%$ & 514.76 & 0.738 \\
\hline
\end{tabular}

\section{References}

1. Shen, W.; Cao, L.; Li, Q.; Zhang, W.; Wang, G. Quantifying $\mathrm{CO}_{2}$ emissions from China's cement industry. Renew. Sustain. Energy Rev. 2015, 50, 1004-1012. [CrossRef]

2. Shen, W.; Cao, L.; Li, Q.; Wen, Z.; Wang, J.; Liu, Y.; Dong, R.; Tan, Y.; Chen, R. Is magnesia cement low carbon? Life cycle carbon footprint comparing with Portland cement. J. Clean. Prod. 2016, 131, 20-27. [CrossRef]

3. Benhelal, E.; Zahedi, G.; Shamsaei, E.; Bahadori, A. Global strategies and potentials to curb $\mathrm{CO}_{2}$ emissions in cement industry. J. Clean. Prod. 2013, 51, 142-161. [CrossRef]

4. Davidovits, J. Geopolymer: Inorganic polymeric new materials. J. Therm. Anal. Calorim. 1991, 37, 1633-1656. [CrossRef]

5. Alomayri, T.; Shaikh, F.U.A.; Low, I.M. Mechanical and thermal properties of ambient cured cotton fabric-reinforced fly ash-based geopolymer composites. Ceram. Int. 2014, 40, 14019-14028. [CrossRef]

6. Graytee, A.; Sanjayan, J.G.; Nazari, A. Development of a high strength fly ash-based geopolymer in short time by using microwave curing. Ceram. Int. 2018, 44, 8216-8222. [CrossRef]

7. Flower, D.J.M.; Sanjayan, J.G. Green house gas emissions due to concrete manufacture. Int. J. Life Cycle Assess. 2007, 12, $282-288$. [CrossRef]

8. Aredes, F.G.M.; Campos, T.M.B.; Machado, J.P.B.; Sakane, K.K.; Thim, G.P.; Brunelli, D.D. Effect of cure temperature on the formation of metakaolinite-based geopolymer. Ceram. Int. 2015, 41, 7302-7311. [CrossRef]

9. Okoye, F.N.; Durgaprasad, J.; Singh, N.B. Effect of silica fume on the mechanical properties of fly ash based-geopolymer concrete. Ceram. Int. 2016, 42, 3000-3006. [CrossRef]

10. Davidovits, J. Geopolymer Chemistry and Applications, 5th ed.; Geopolymer Institute: Saint-Quentin, France, 2011.

11. Çevik, A.; Alzeebaree, R.; Humur, G.; Niş, A.; Gülşan, M.E. Effect of nano-silica on the chemical durability and mechanical performance of fly ash based geopolymer concrete. Ceram. Int. 2018, 44, 12253-12264. [CrossRef]

12. Castel, A.; Foster, S.J. Bond strength between blended slag and Class Fly ash geopolymer concrete with steel reinforcement. Cem. Concr. Res. 2015, 72, 48-53. [CrossRef]

13. Albitar, M.; Ali, M.S.M.; Visintin, P.; Drechsler, M. Effect of granulated lead smelter slag on strength of fly ash-based geopolymer concrete. Constr. Build. Mater. 2015, 83, 128-135. [CrossRef]

14. Xu, F.; Deng, X.; Peng, C.; Zhu, J.; Chen, J. Mix design and flexural toughness of PVA fiber reinforced fly ash-geopolymer composites. Constr. Build. Mater. 2017, 150, 179-189. [CrossRef]

15. Xu, H.; Gong, W.; Syltebo, L.; Izzo, K.; Lutze, W.; Pegg, I.L. Effect of blast furnace slag grades on fly ash based geopolymer waste forms. Fuel 2014, 133, 332-340. [CrossRef]

16. Gao, X.; Yu, Q.; Brouwers, H.J.H. Properties of alkali activated slag-fly ash blends with limestone addition. Cem. Concr. Compos. 2015, 59, 119-128. [CrossRef]

17. Sarkar, M.; Dana, K.; Das, S. Microstructural and phase evolution in metakaolin geopolymers with different activators and added aluminosilicate fillers. J. Mol. Struct. 2015, 1098, 110-118. [CrossRef]

18. Tchakoute, H.K.; Rüscher, C.H.; Djobo, J.N.Y.; Kenne, B.B.D.; Njopwouo, D. Influence of gibbsite and quartz in kaolin on the properties of metakaolin-based geopolymer cements. Appl. Clay Sci. 2015, 107, 188-194. [CrossRef]

19. Yang, K.H.; Song, J.K.; Song, K.I. Assessment of $\mathrm{CO}_{2}$ reduction of alkali-activated concrete. J. Clean. Prod. 2013, 39, $265-272$. [CrossRef]

20. Shojaei, M.; Behfarnia, K.; Mohebi, R. Application of alkali-activated slag concrete in railway sleepers. Mater. Des. 2015, 69, 89-95. [CrossRef]

21. Zejak, R.; Nikolic, I.; Blecic, D.; Radmilovi, V.V.; Radmilovi, V.R. Mechanical and microstructural properties of the fly-ash-based geopolymer paste and mortar. Mater. Tehnol. 2013, 47, 535-540.

22. Chindaprasirt, P.; Chareerat, T.; Sirivivatnanon, V. Workability and strength of coarse high calcium fly ash geopolymer. Cem. Concr. Compos. 2007, 29, 224-229. [CrossRef]

23. Islam, A.; Alengaram, U.J.; Jumaat, M.Z.; Bashar, I.I. The development of compressive strength of ground granulated blast furnace slag-palm oil fuel ash-fly ash based geopolymer mortar. Mater. Des. 2014, 56, 833-841. [CrossRef]

24. Ranjbar, N.; Mehrali, M.; Alengaram, U.J.; Simon, H.; Jumaat, M.Z. Compressive strength and microstructural analysis of fly ash/palm oil fuel ash based geopolymer mortar. Constr. Build. Mater. 2014, 65, 532-539. [CrossRef] 
25. Zhang, Z.; Wang, H.; Zhu, Y.; Andrew, R.; John, L.P.; Frank, B. Using fly ash to partially substitute metakaolin in geopolymer synthesis. Appl. Clay Sci. 2014, 88, 194-201. [CrossRef]

26. Park, S.S.; Kang, H.Y. Characterization of fly ash-pastes synthesized at different activator conditions. Korean J. Chem. Eng. 2008, 25, 78-83. [CrossRef]

27. Sun, Y.; Fu, K.; Zhu, H.; Zhu, T. Silica-alumina molar ratio and some factors effect on the synthesis of zeolites from fly ash. J. Coal Sci. Eng. 2009, 15, 430-433. [CrossRef]

28. Guo, X.; Shi, H.; Dick, W.A. Utilization of thermally treated flue gas desulfurization (FGD) gypsum and class-C fly ash (CFA) to prepare CFA-based geopolymer. J. Wuhan Univ. Technol. 2013, 28, 132-138. [CrossRef]

29. Garcia-Lodeiro, I.; Palomo, A.; Fernandez-Jimenez, A. Alkali-aggregate reaction in activated fly ash systems. Cem. Concr. Res. 2007, 37, 175-183. [CrossRef]

30. Rao, S.M.; Acharya, I.P. Synthesis and Characterization of Fly Ash Geopolymer Sand. J. Mater. Civ. Eng. 2014, 26, 912-917. [CrossRef]

31. Lee, W.K.W.; Van Deventer, J.S.J. The interface between natural siliceous aggregates and geopolymers. Cem. Concr. Res. 2004, 34, 195-206. [CrossRef]

32. Temuujin, J.; Riessen, A.V.; MacKenzie, K.J.D. Preparation and characterisation of fly ash based geopolymer mortars. Constr. Build. Mater. 2010, 24, 1906-1910. [CrossRef]

33. Brough, A.R.; Atkinson, A. Sodium silicate-based alkali-activated slag mortars Part I. Strength, hydration and microstructure. Cem. Concr. Res. 2002, 32, 865-879. [CrossRef]

34. Nath, P.; Sarker, P.K. Effect of GGBFS on setting, workability and early strength properties of fly ash geopolymer concrete cured in ambient condition. Constr. Build. Mater. 2014, 66, 163-171. [CrossRef]

35. Lee, N.K.; Lee, H.K. Setting and mechanical properties of alkali-activated fly ash/slag concrete manufactured at room temperature. Constr. Build. Mater. 2013, 47, 1201-1209. [CrossRef]

36. Singh, B.; Rahman, M.R.; Paswan, R.; Bhattacharyya, S.K. Effect of activator concentration on the strength, ITZ and drying shrinkage of fly ash/slag geopolymer concrete. Constr. Build. Mater. 2016, 118, 171-179. [CrossRef]

37. Yang, K.H.; Song, J.K.; Lee, K.S.; Ashour, A.F. Flow and compressive strength of alkali-activated mortars. ACI Mater. J. 2009, 106, 50-58.

38. Yang, K.H.; Song, J.K. Workability loss and compressive strength development of cementless mortars activated by combination of sodium silicate and sodium hydroxide. J. Mater. Civ. Eng. 2009, 21, 119-127. [CrossRef]

39. Chuah, S.; Duan, W.; Pan, Z.; Hunter, E.; Korayem, A.H.; Zhao, X.; Collins, F.; Sanjayan, J.G. The properties of fly ash based geopolymer mortars made with dune sand. Mater. Des. 2016, 92, 571-578. [CrossRef]

40. ASTM International. Standard Specification for Coal Fly Ash and Raw or Calcined Natural Pozzolan for Use in Concrete; ASTM C618-03; ASTM: West Conshohocken, PA, USA, 2003.

41. Gu, G.; Xu, F.; Ruan, S.; Huang, X.; Zhu, J.; Peng, C. Influence of precast foam on the pore structure and properties of fly ash-based geopolymer foams. Constr. Build. Mater. 2020, 256, 119410. [CrossRef]

42. Gu, G.; Xu, F.; Huang, X.; Ruan, S.; Peng, C.; Lin, J. Foamed geopolymer: The relationship between rheological properties of geopolymer paste and pore-formation mechanism. J. Clean. Prod. 2020, 277, 123238. [CrossRef]

43. ASTM International. Standard Specification for Ready-Mixed Concrete; ASTM C94; ASTM: West Conshohocken, PA, USA, 2015.

44. ISO. Cement-Test methods—Determination of Strength; ISO 679; ISO: Geneva, Switzerland, 1989.

45. AQSIQ; SAC. Sand for Construction; GB/T 14684-2011; GB: Beijing, China, 2011.

46. ASTM International. Standard Specification for Flow Table for Use in Tests of Hydraulic Cement; ASTM C230/C230M; ASTM: West Conshohocken, PA, USA, 2003.

47. ASTM International. Standard Practice for Mechanical Mixing of Hydraulic Cement Pastes and Mortars of Plastic Consistency; ASTM C305; ASTM: West Conshohocken, PA, USA, 2014.

48. ASTM International. Standard Test Method for Flexural Strength of Hydraulic-Cement Mortars; ASTM C348; ASTM: West Conshohocken, PA, USA, 2018.

49. ASTM International. Standard Test Method for Compressive Strength of Cylindrical Concrete Specimens; ASTM C39; ASTM: West Conshohocken, PA, USA, 1996.

50. Xu, F.; Zhou, M.; Chen, J.; Ruan, S. Mechanical performance evaluation of polyester fiber and SBR latex compound-modified cement concrete road overlay material. Constr. Build. Mater. 2014, 63, 142-149. [CrossRef]

51. Xu, F.; Chen, J.; Ruan, S.; Zhou, M. Influence of PP fiber and SBR latex on the mechanical properties of crumb rubber mortar. J. Appl. Polym. Sci. 2014, 131, 64-73. [CrossRef]

52. Arioz, E.; Arioz, O.; Kockar, O.M. Geopolymer Synthesis with Low Sodium Hydroxide Concentration. Iran. J. Sci. Technol. Trans. Civ. Eng. 2020, 44, 525-533. [CrossRef]

53. Bohra, V.; Nerella, R.; Madduru, S.; Rohith, P. Microstructural characterization of fly ash based geopolymer. Mater. Today Proc. 2020, 27, 1625-1629. [CrossRef]

54. Davidovits, J. Geopolymers: Inorganic polymeric new materials. J. Mater. Educ. 1994, 16, 91-139. [CrossRef]

55. Lecomte, I.; Liegeois, M.; Rulmont, A.; Cloots, R.; Maseri, F. Synthesis and characterization of new inorganic polymeric composites based on kaolin or white clay and on ground-granulated blast furnace slag. J. Mater. Res. 2003, 18, 2571-2579. [CrossRef] 
56. Lizcano, M.; Kim, H.S.; Basu, S.; Radovic, M. Mechanical properties of sodium and potassium activated metakaolin-based geopolymers. J. Mater. Sci. 2012, 47, 2607-2616. [CrossRef]

57. Zhang, Y.; Sun, W.; Li, Z. Hydration process of potassium polysialate (K-PSDS) geopolymer cement. Adv. Cem. Res. 2005, 17, 23-28. [CrossRef]

58. Liew, Y.M.; Heah, C.Y.; Mohd Mustafa, A.B.; Kamarudin, H. Structure and properties of clay-based geopolymer cements: A review. Prog. Mater. Sci. 2016, 83, 595-629. [CrossRef]

59. Gu, G.; Xu, F.; Zhou, Y.; Huang, X.; Li, Y. Formation mechanism of early strength in geopolymer based on molar ratio of mineral components. Acta Mater. Compos. Sin. 2020, 37, 2036-2044.

60. Zhang, P.; Wang, K.; Wang, J.; Guo, J.; Ling, Y. Macroscopic and microscopic analyses on mechanical performance of metakaolin/fly ash based geopolymer mortar. J. Clean. Prod. 2021, 294, 126193. [CrossRef] 